\title{
SYNTHESIS OF 1,3,6-TRISUBSTITUTED AZULENES
}

Teppo O. Leino, ${ }^{*}{ }^{\dagger}$ Marcus Baumann, ${ }^{\ddagger}$ Jari Yli-Kauhaluoma, ${ }^{\dagger}$ Ian R. Baxendale ${ }^{\ddagger}$ and Erik A. A. Wallén ${ }^{\dagger}$

'Division of Pharmaceutical Chemistry and Technology, Faculty of Pharmacy, University of Helsinki, Viikinkaari 5 E, FI-00014 Helsinki, Finland

${ }^{ \pm}$Department of Chemistry, Durham University, South Road, Durham DH1 3LE, United Kingdom

teppo.leino@helsinki.fi

\section{Table of contents}

${ }^{1} \mathrm{H}$ and ${ }^{13} \mathrm{C}$ NMR spectra. 
${ }^{1} \mathrm{H}$ NMR (400 MHz, $\mathrm{CDCl}_{3}$ ): Compound 5

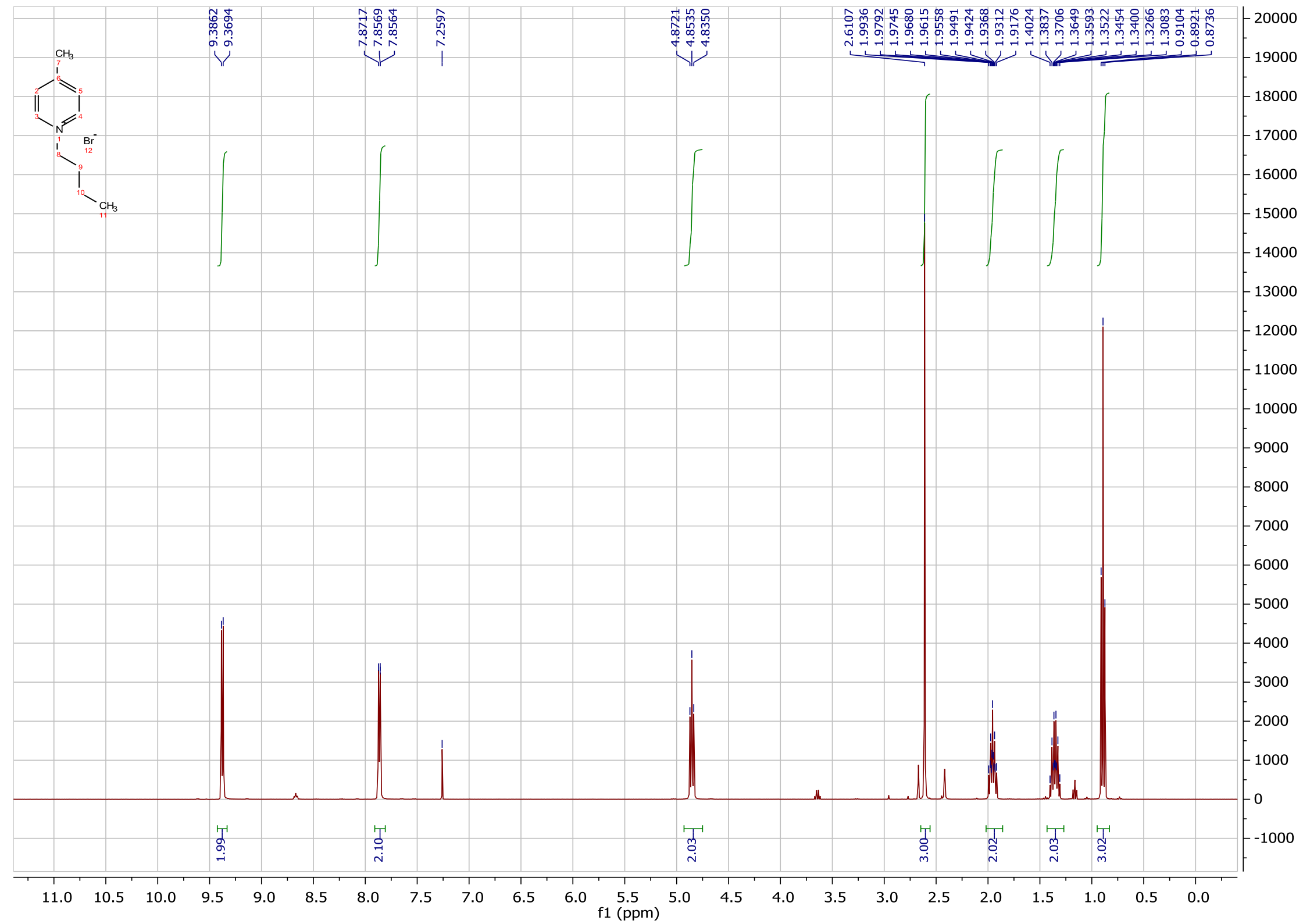


${ }^{13} \mathrm{C}$ NMR (101 MHz, CDCl 3 ): Compound 5

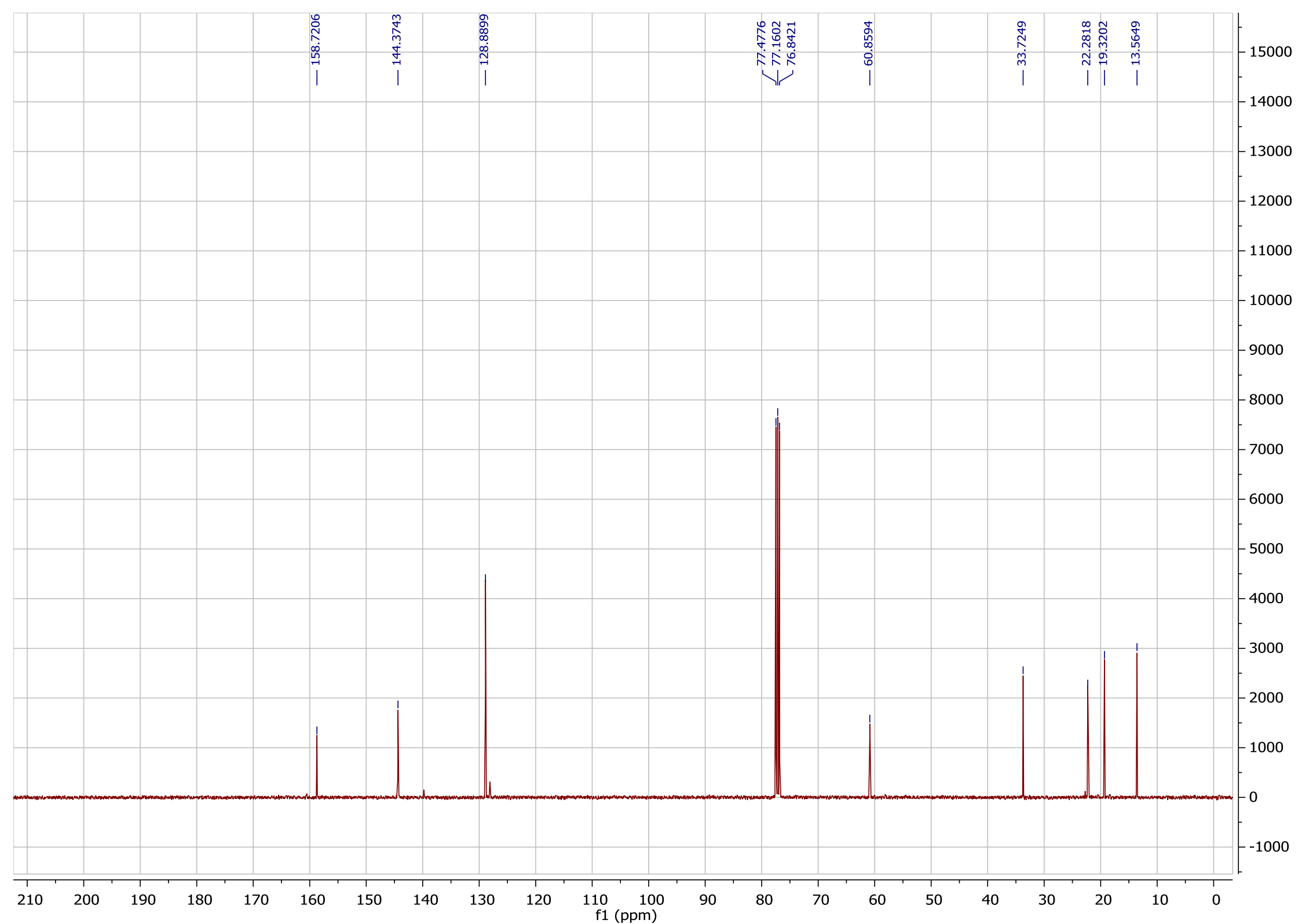


${ }^{1} \mathrm{H}$ NMR (400 MHz, $\mathrm{CDCl}_{3}$ ): Compound 3

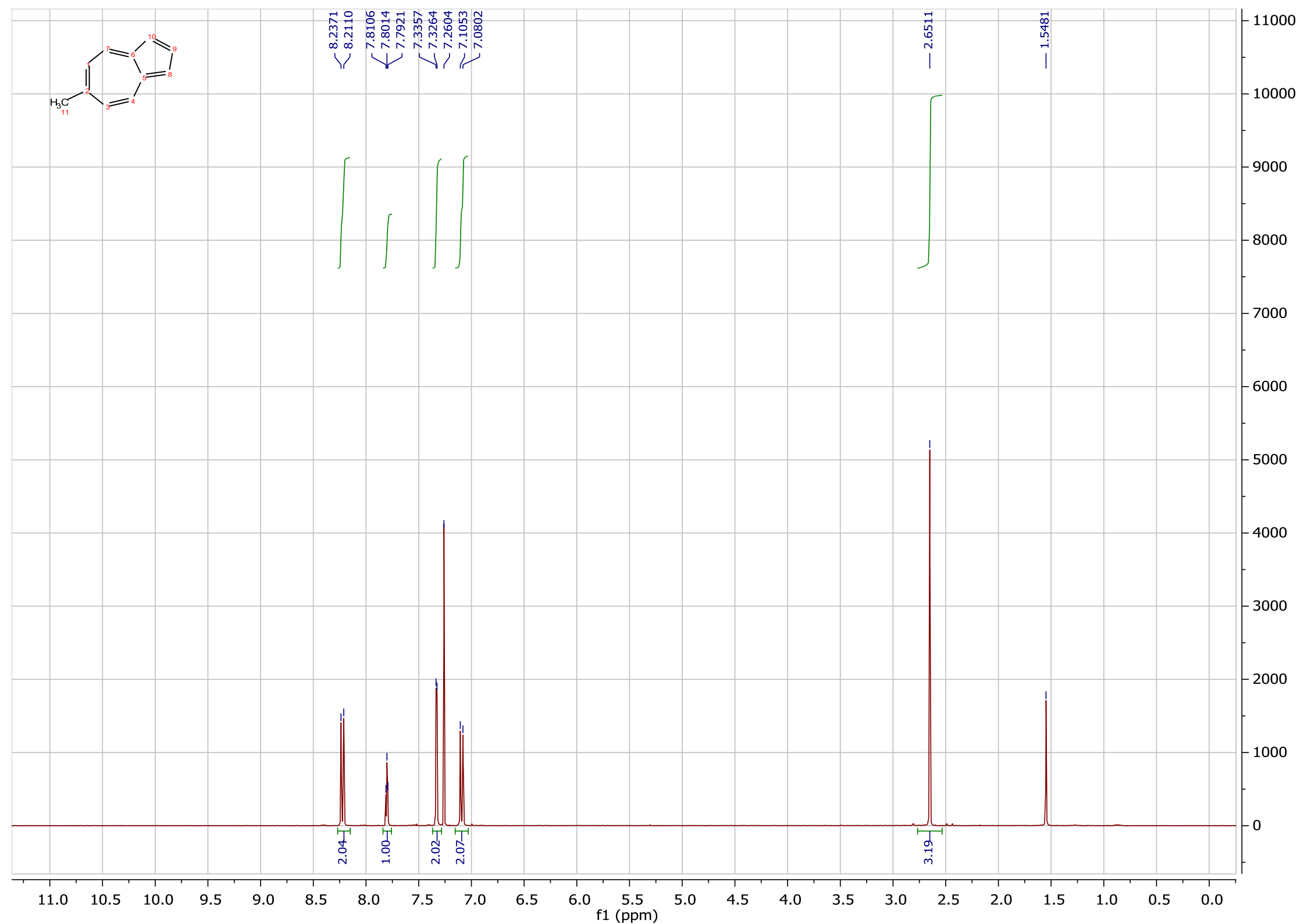


${ }^{13}$ C NMR (101 MHz, $\left.\mathrm{CDCl}_{3}\right)$ : Compound 3

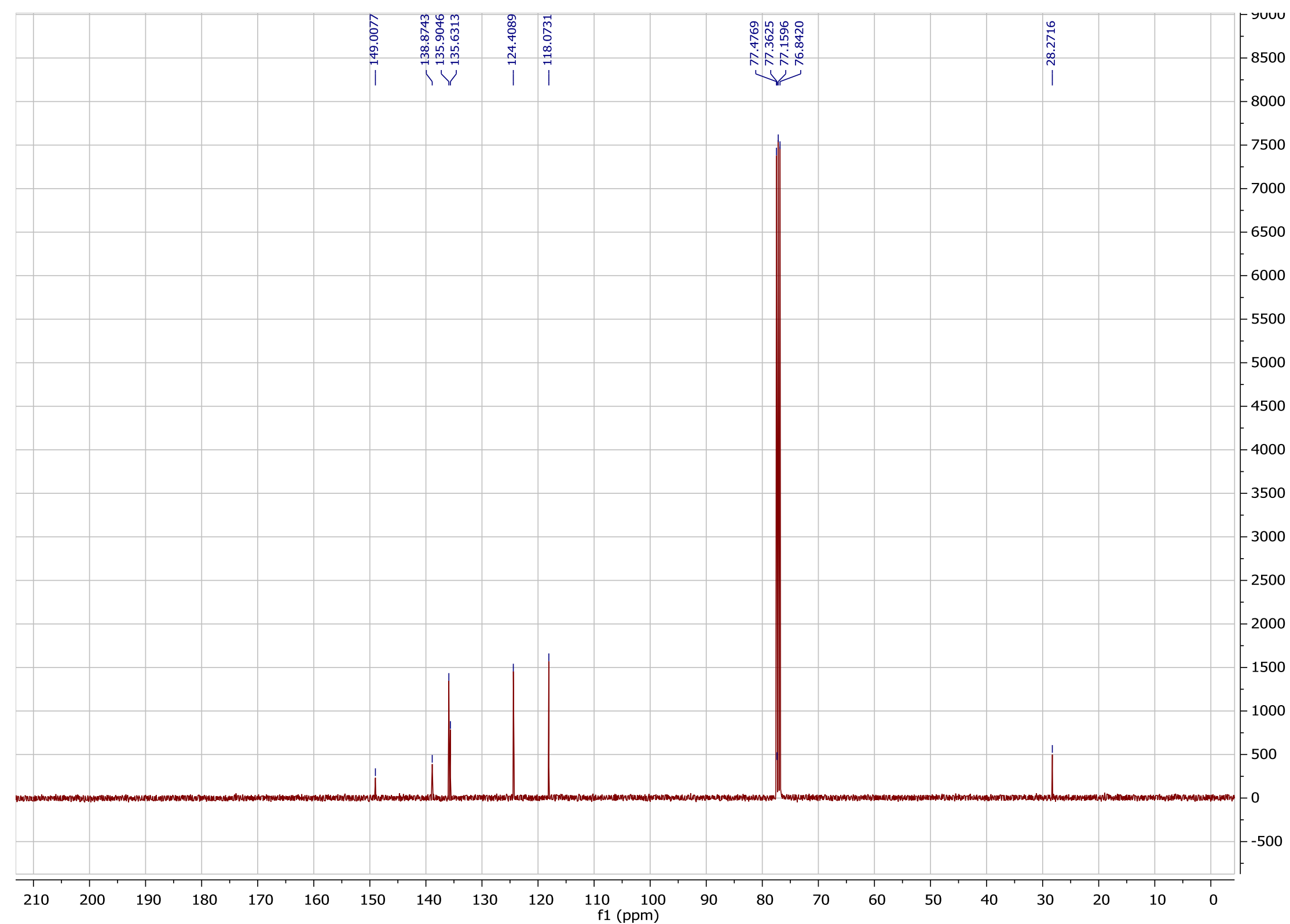


${ }^{1} \mathrm{H}$ NMR (400 MHz, $\mathrm{CDCl}_{3}$ ): Compound 6

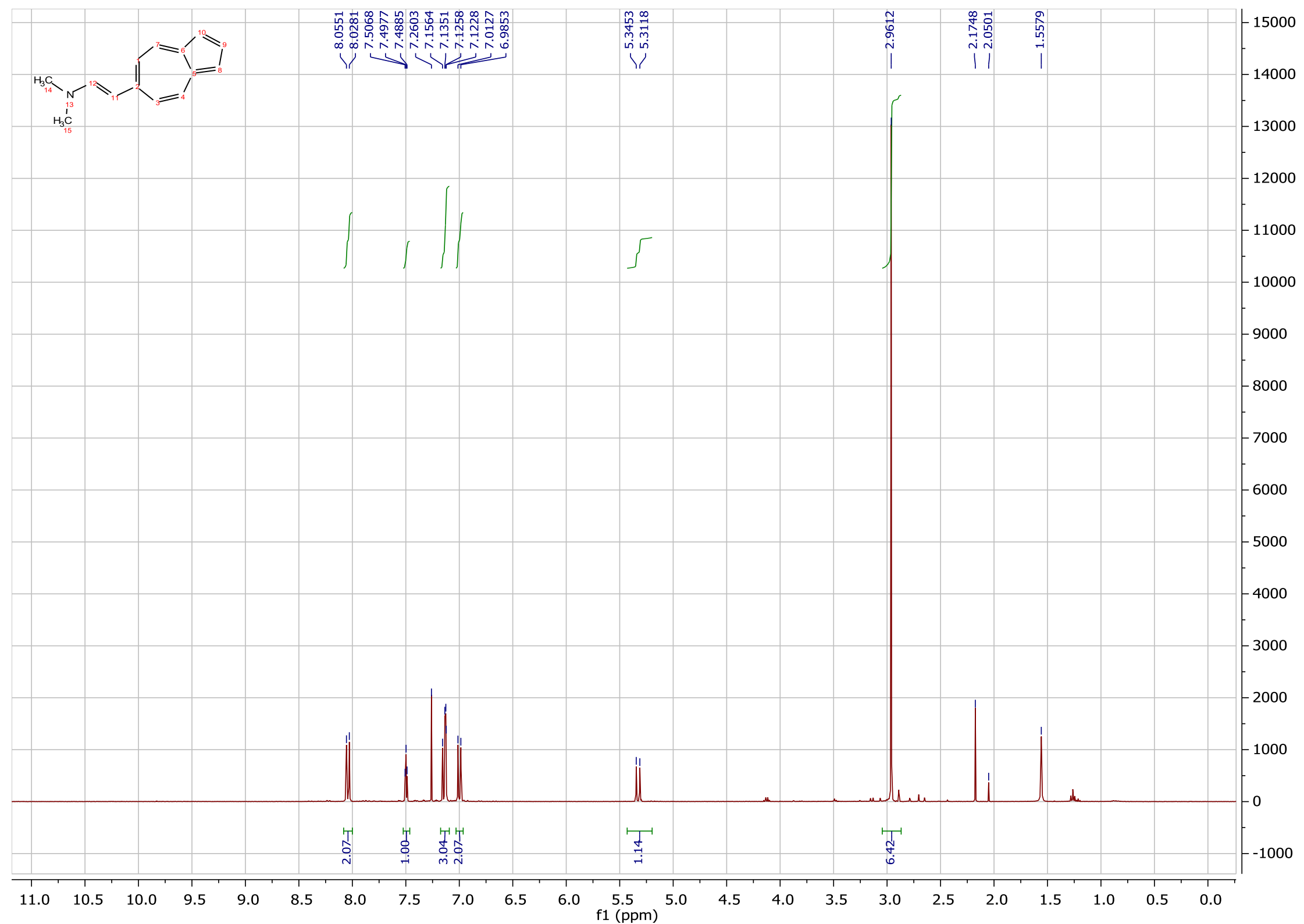


${ }^{13}$ C NMR (101 MHz, $\left.\mathrm{CDCl}_{3}\right)$ : Compound 6

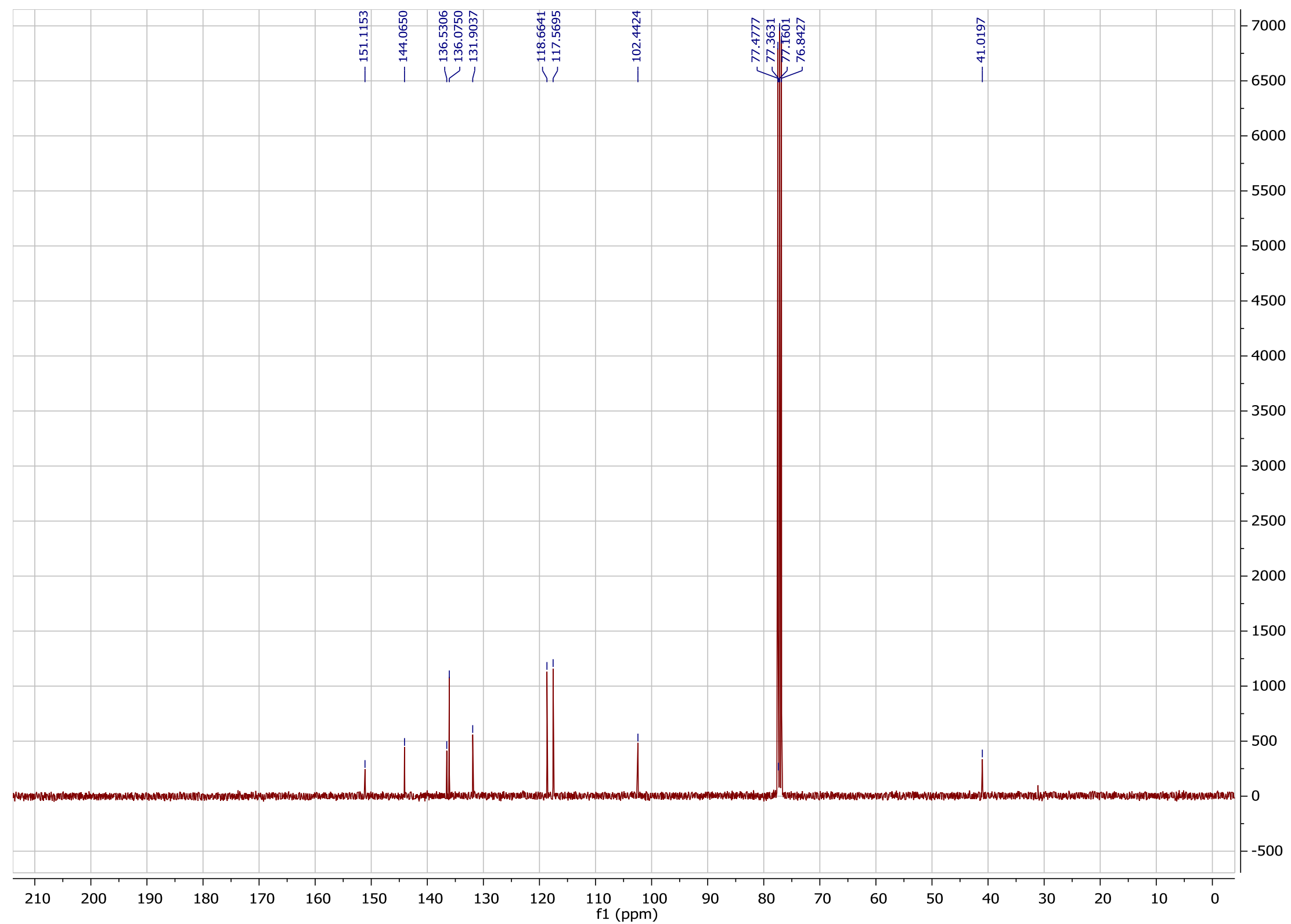


${ }^{1} \mathrm{H}$ NMR (400 MHz, $\mathrm{CDCl}_{3}$ ): Compound 7

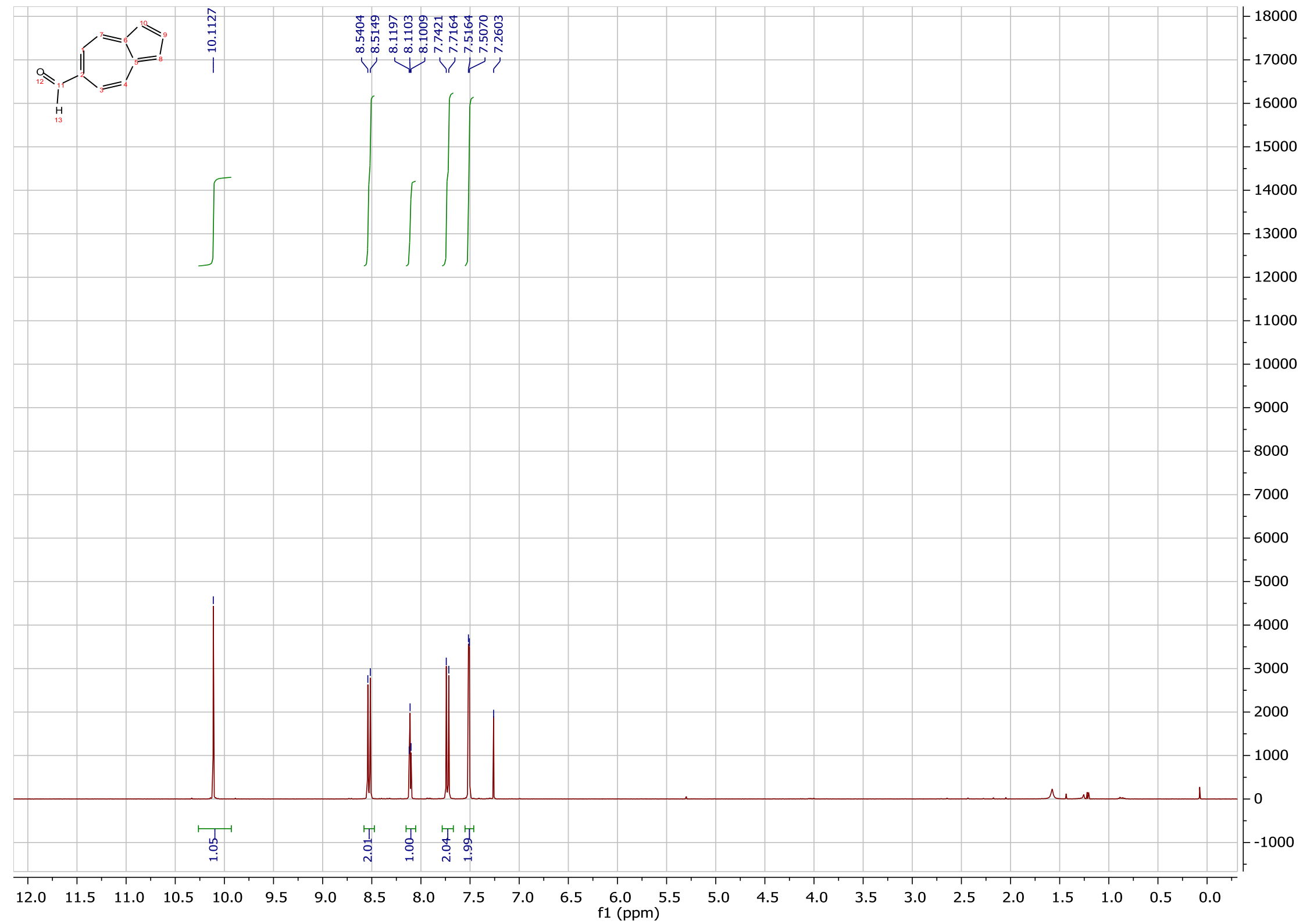


${ }^{13}$ C NMR (101 MHz, $\left.\mathrm{CDCl}_{3}\right)$ : Compound 7

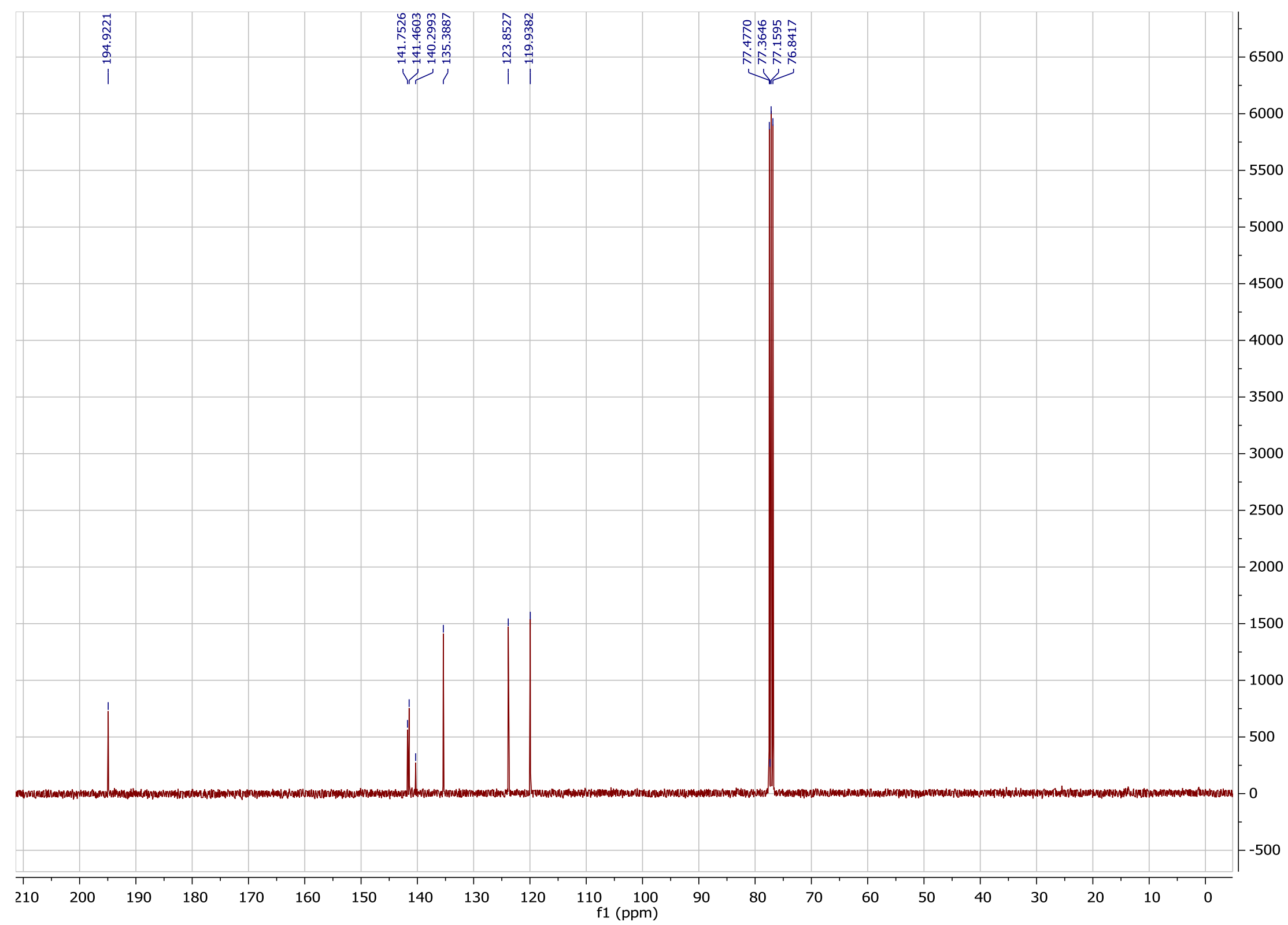


${ }^{1}$ H NMR (300 MHz, $\mathrm{CDCl}_{3}$ ): Compound 8

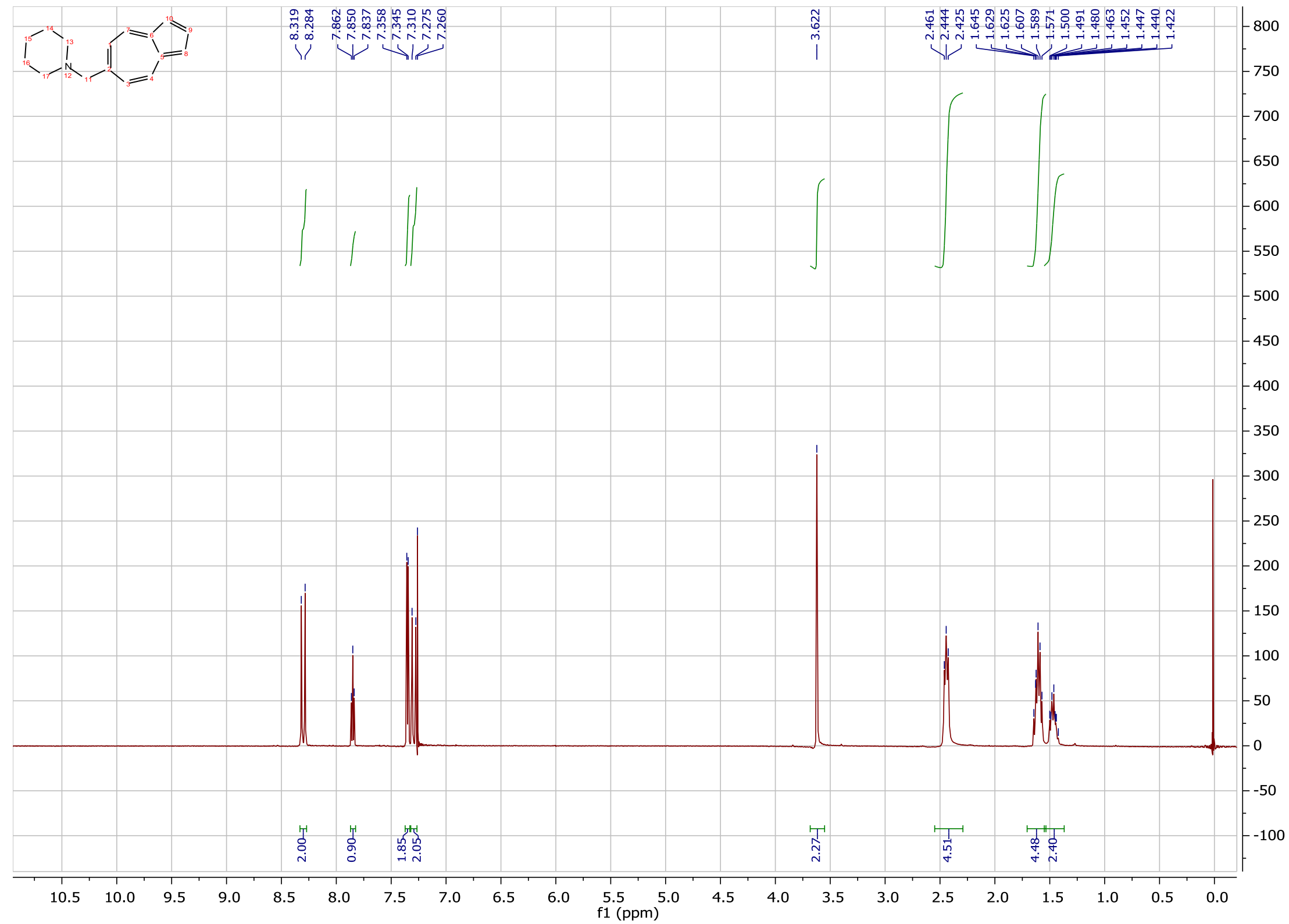


${ }^{13} \mathrm{C}$ NMR (75 $\mathrm{MHz}, \mathrm{CDCl}_{3}$ ): Compound 8

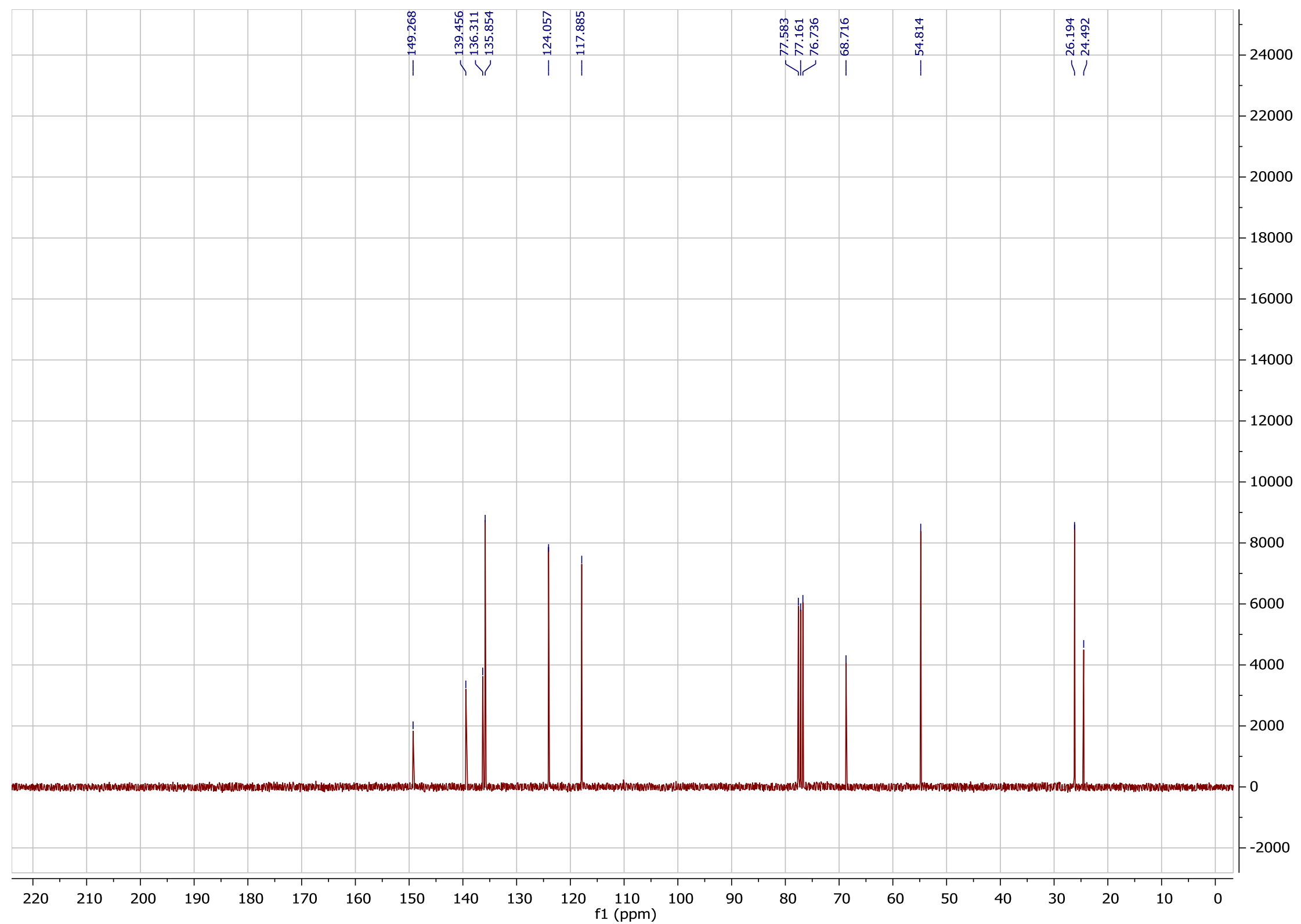


${ }^{1}$ H NMR (300 MHz, acetone- $d_{6}$ ): Compound 10

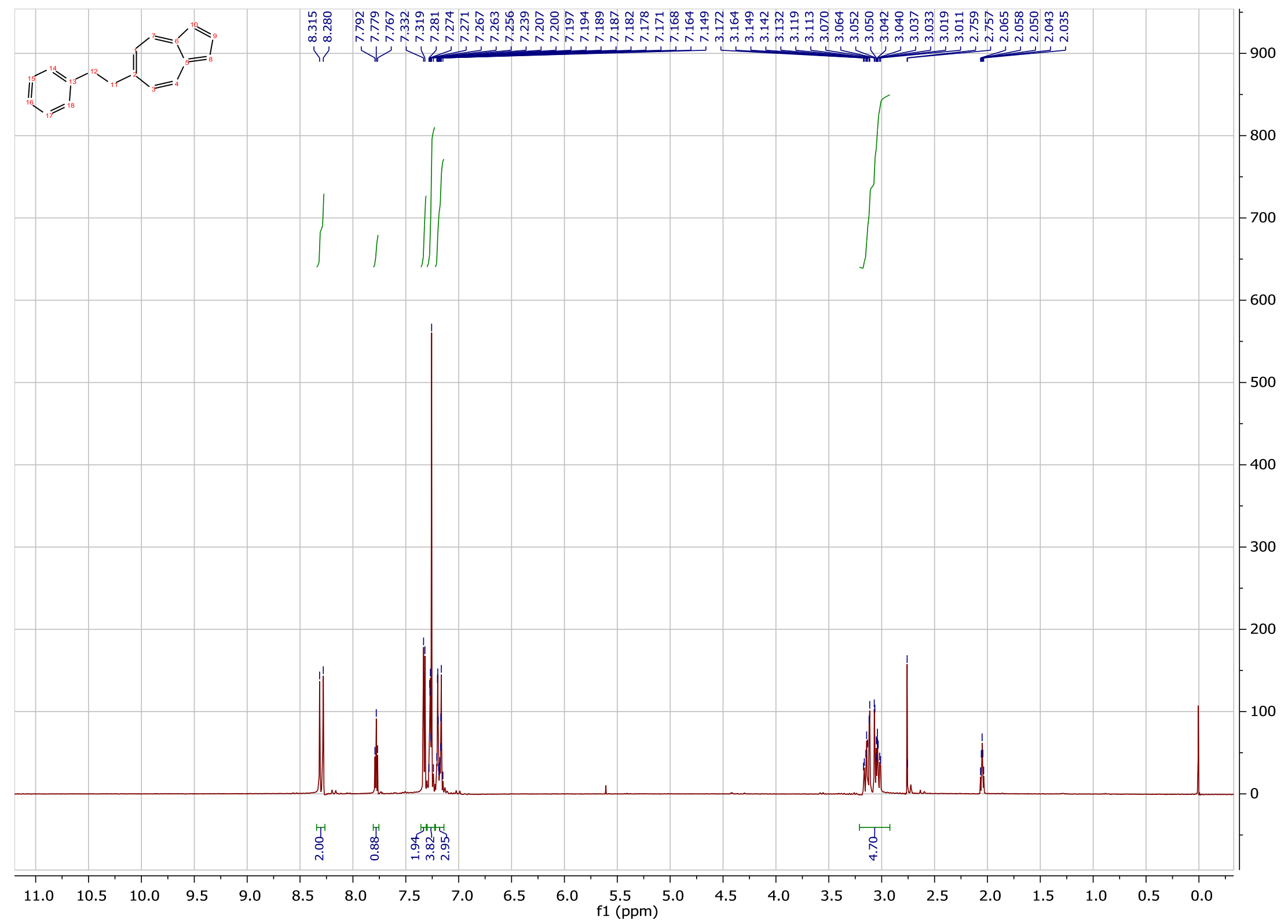


${ }^{13}$ C NMR (75 MHz, acetone- $\left.d_{6}\right)$ : Compound 10

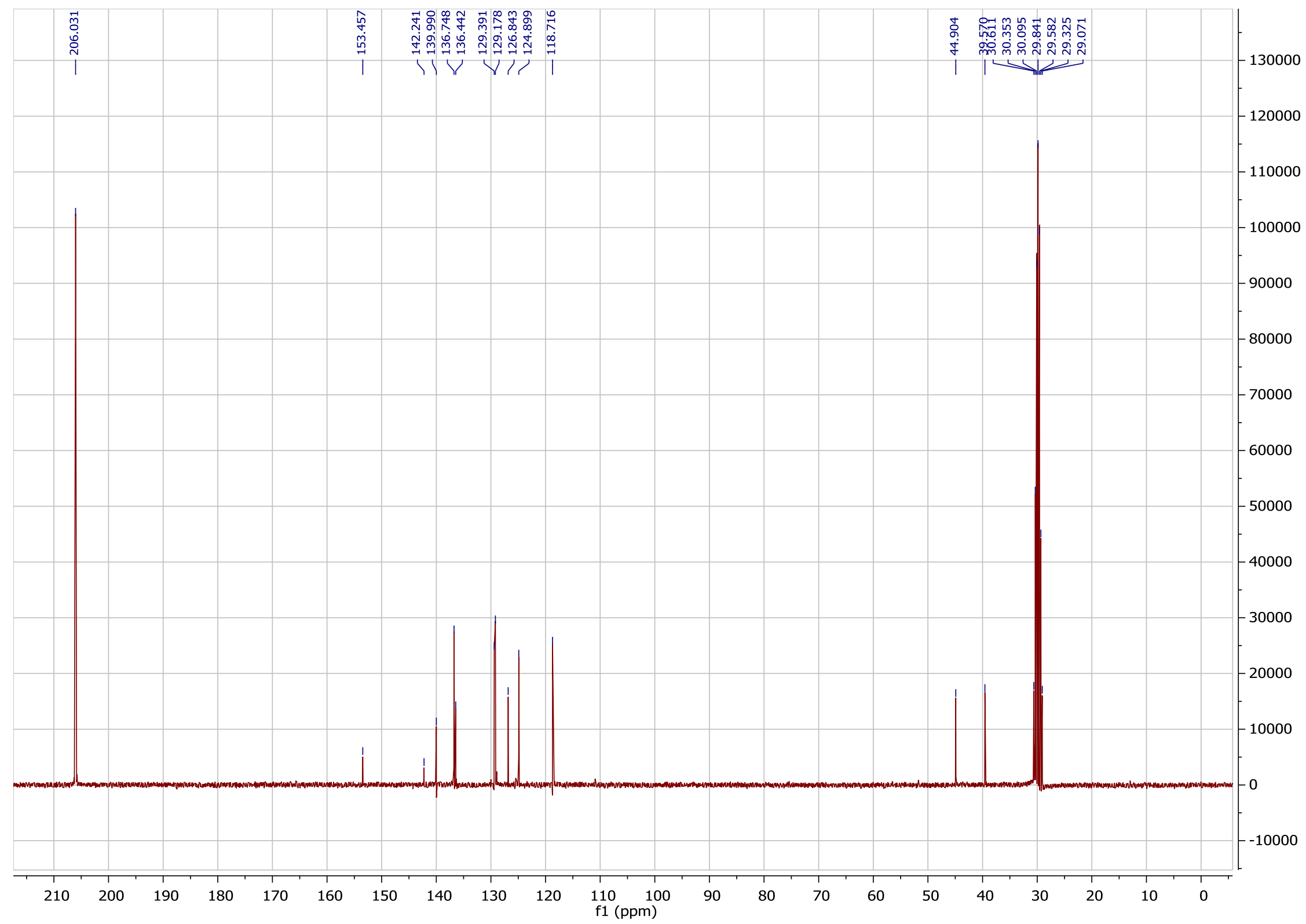


${ }^{1}$ H NMR (400 MHz, $\left.\mathrm{CDCl}_{3}\right)$ : Compound 11

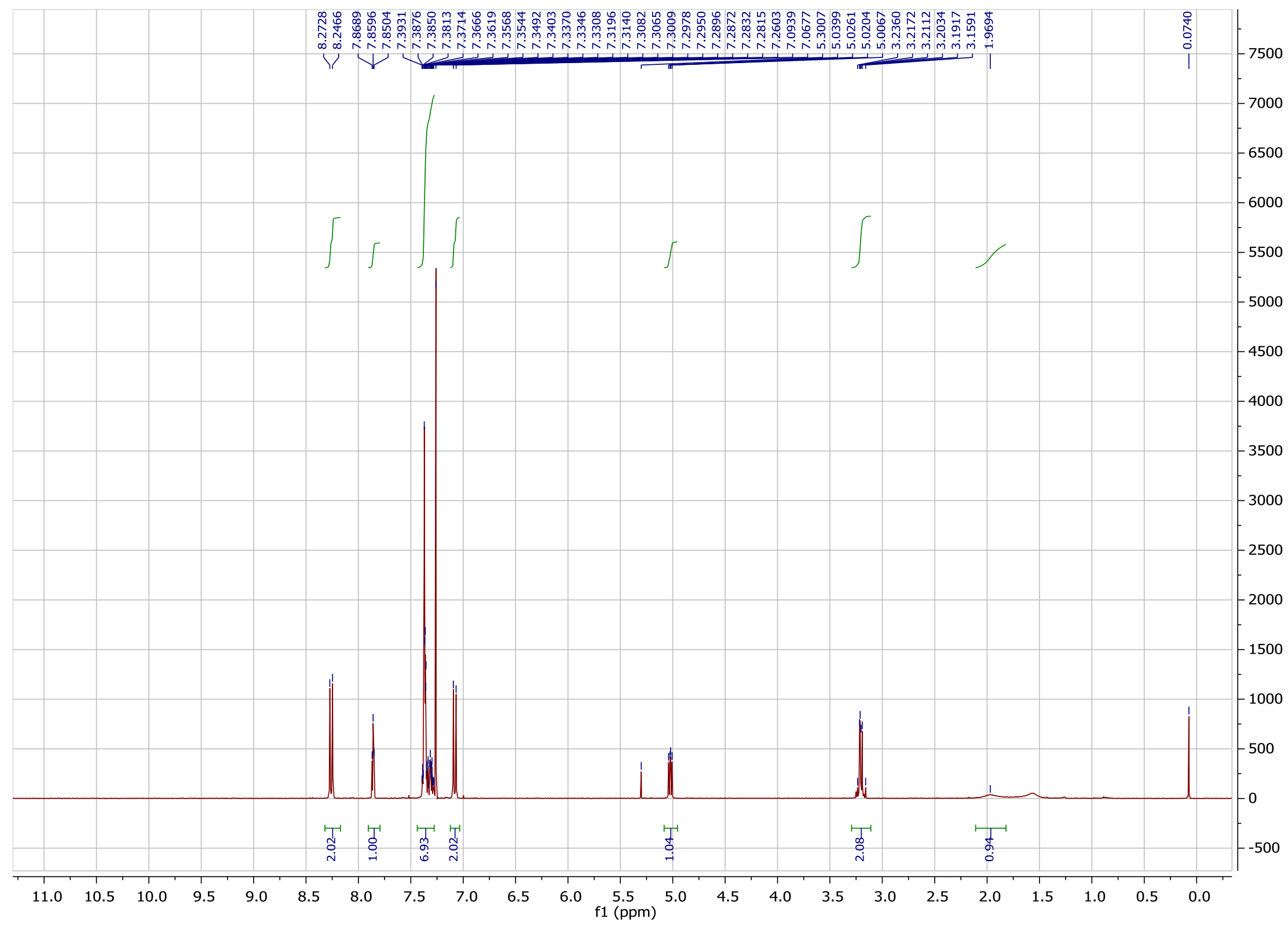


${ }^{13}$ C NMR (101 MHz, $\left.\mathrm{CDCl}_{3}\right)$ : Compound 11

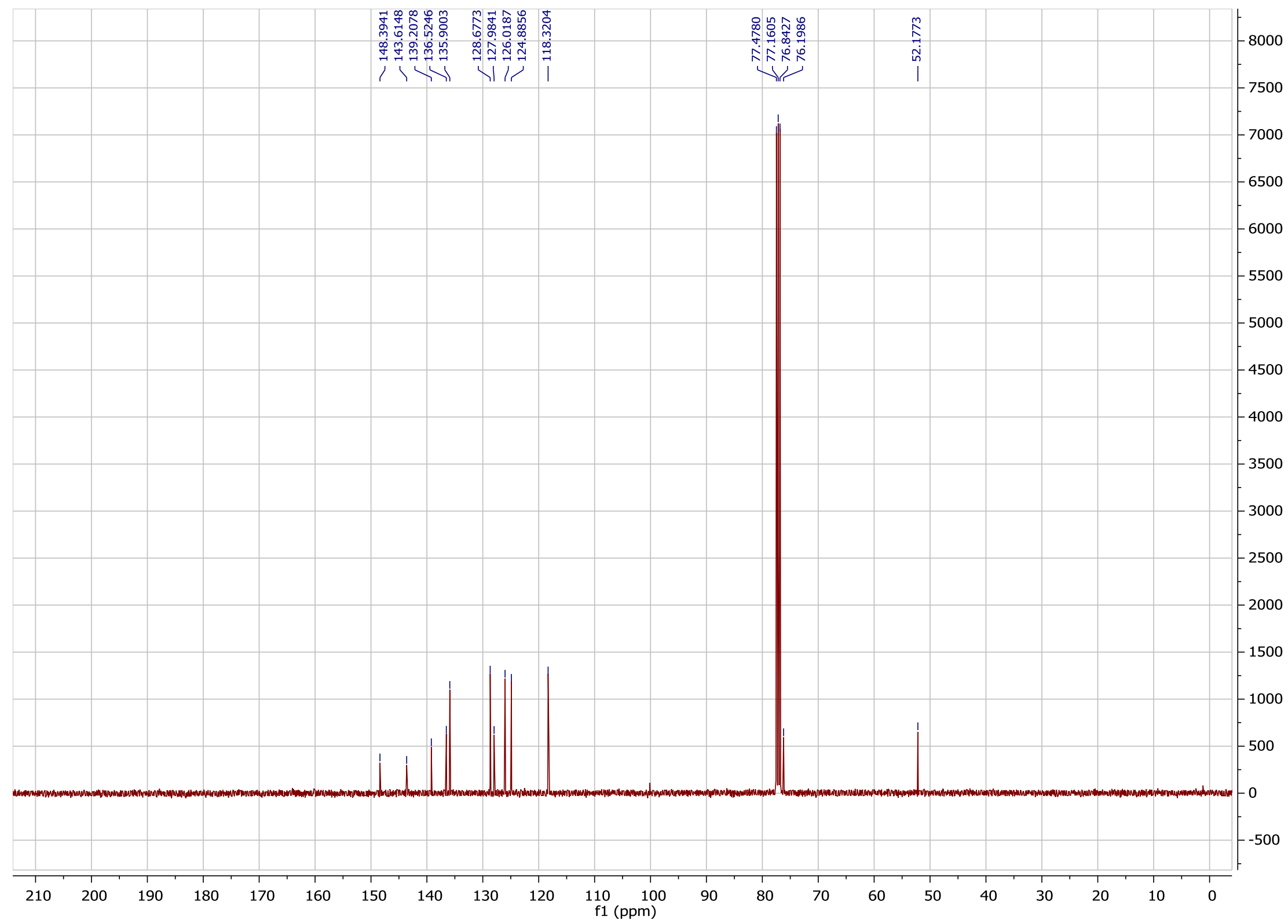


${ }^{1} \mathrm{H}$ NMR (400 MHz, $\left.\mathrm{CDCl}_{3}\right)$ : Compound 12

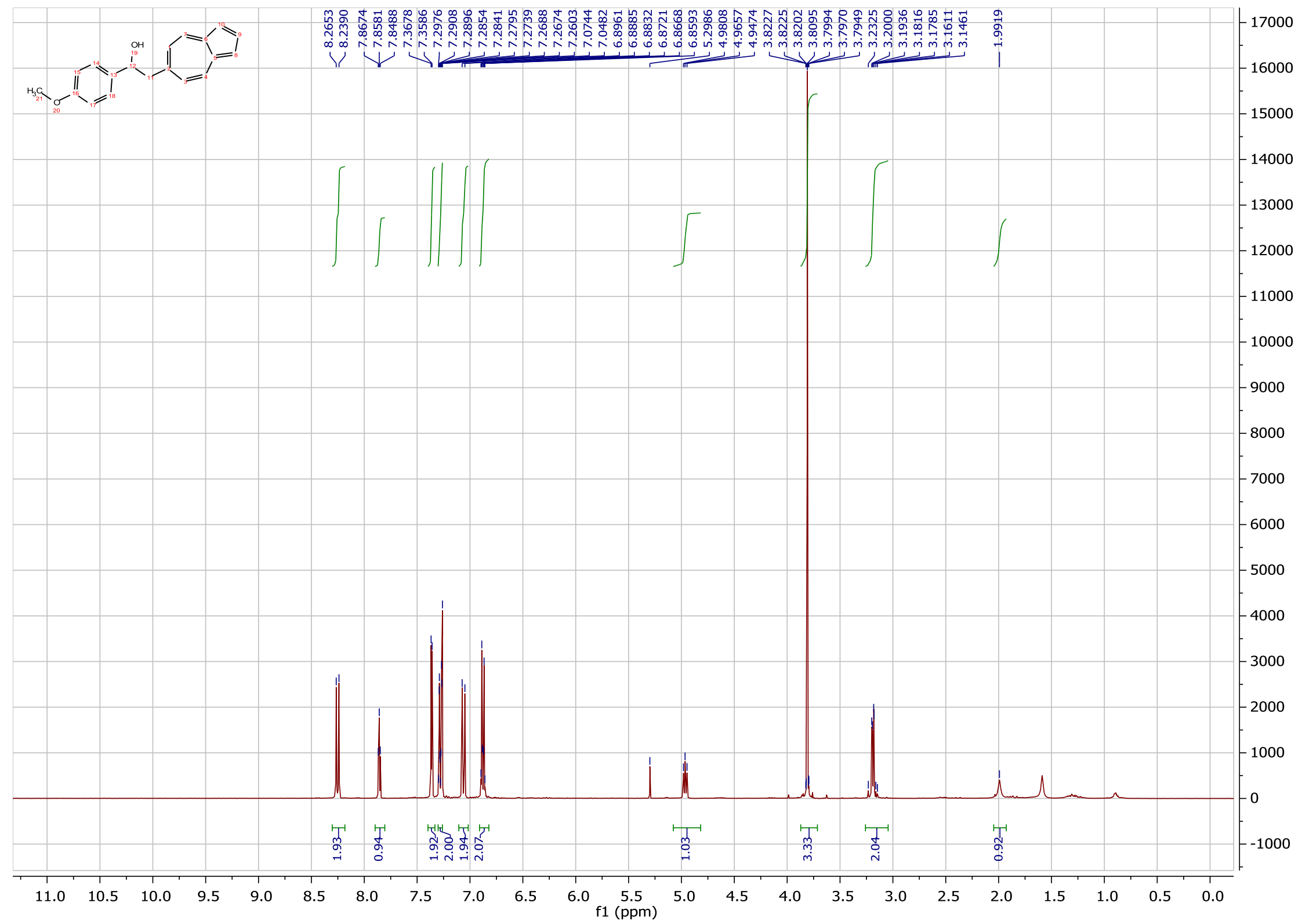


${ }^{1}$ C NMR (101 MHz, $\left.\mathbf{C D C l}_{3}\right)$ : Compound 12

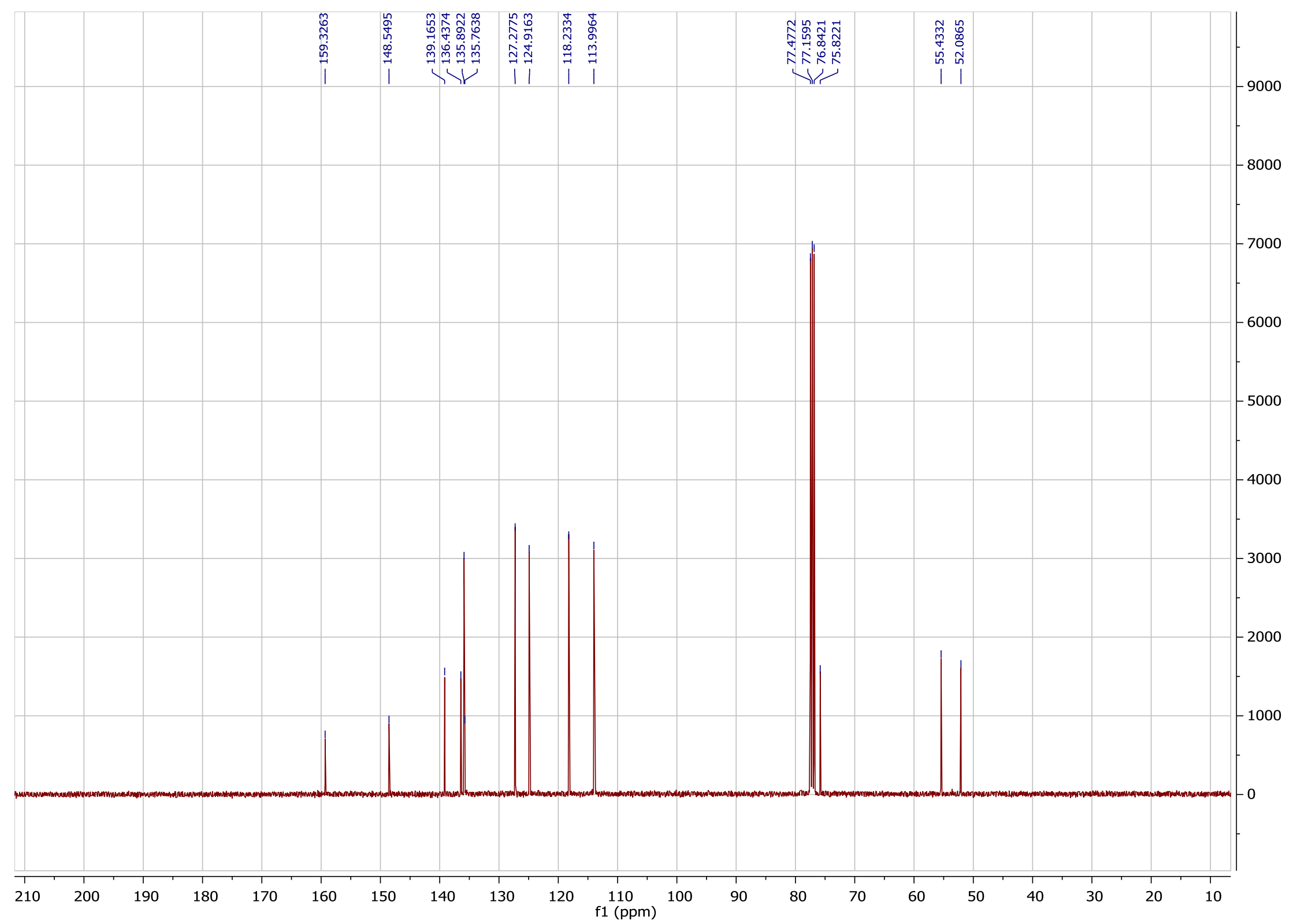


${ }^{1}$ H NMR (300 MHz, $\left.\mathrm{CDCl}_{3}\right)$ : Compound 13

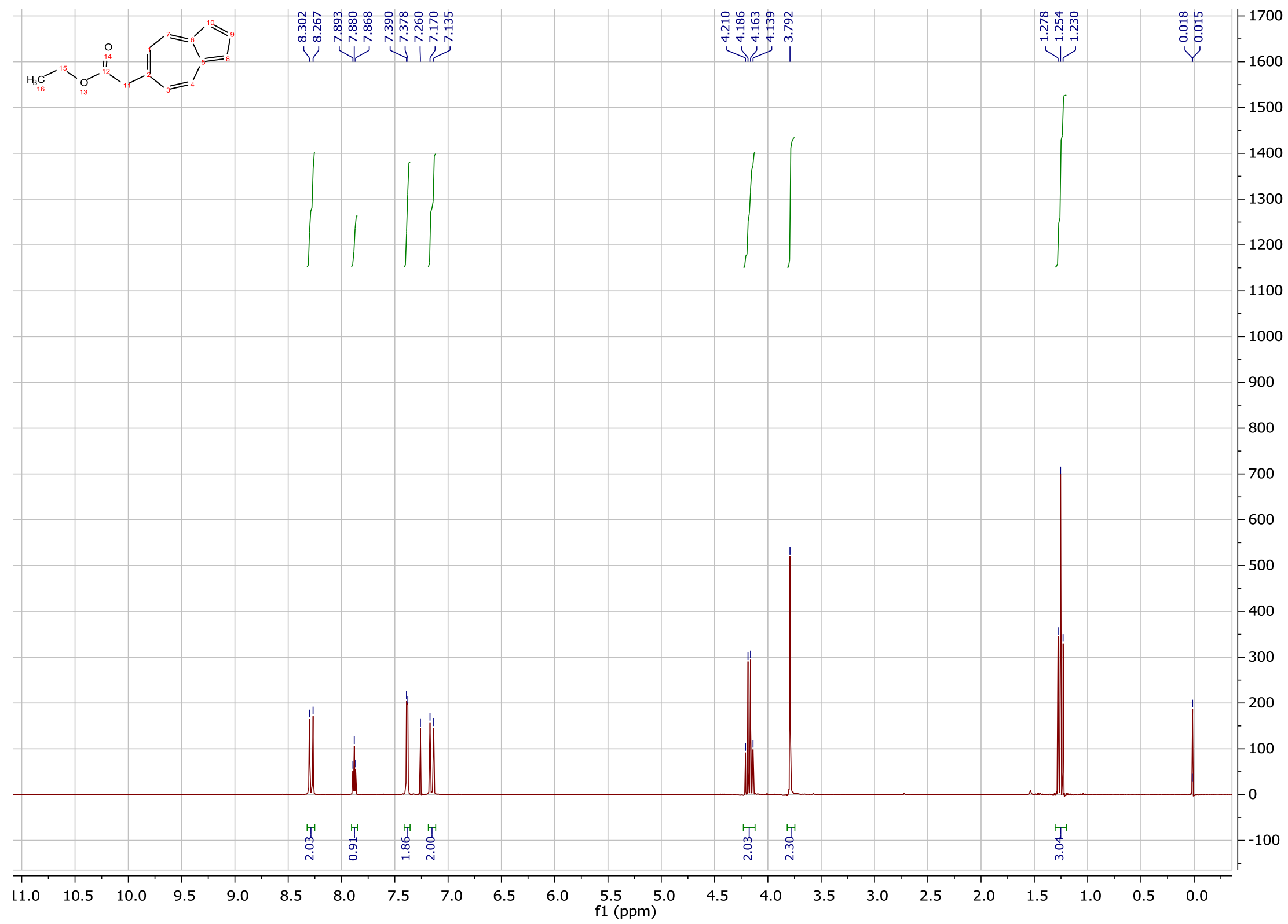


${ }^{13}$ C NMR (75 MHz, $\mathrm{CDCl}_{3}$ ): Compound 13

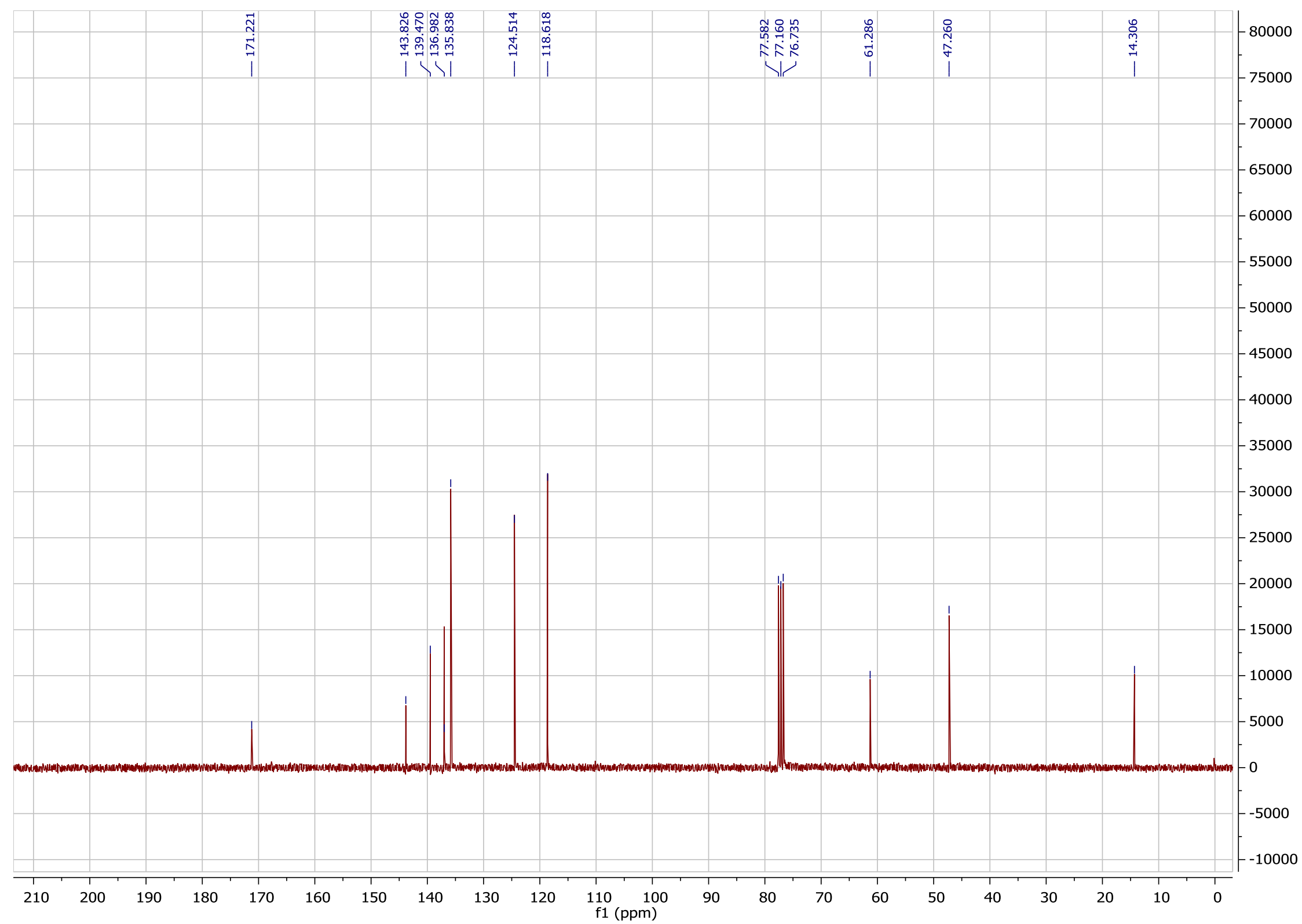


${ }^{1}$ H NMR (300 MHz, $\mathrm{CDCl}_{3}$ ): Compound 14

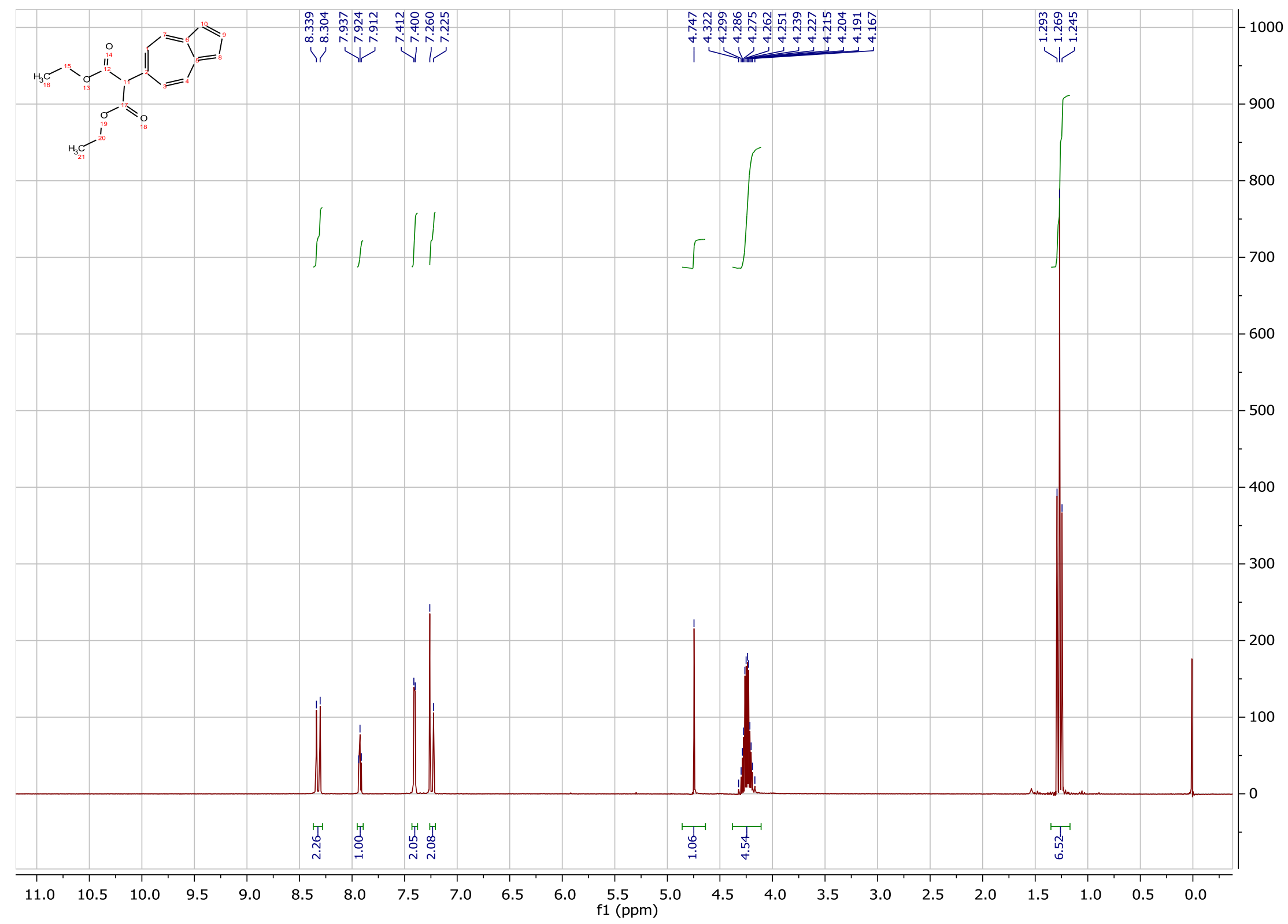


${ }^{13}$ C NMR (75 MHz, $\mathrm{CDCl}_{3}$ ): Compound 14

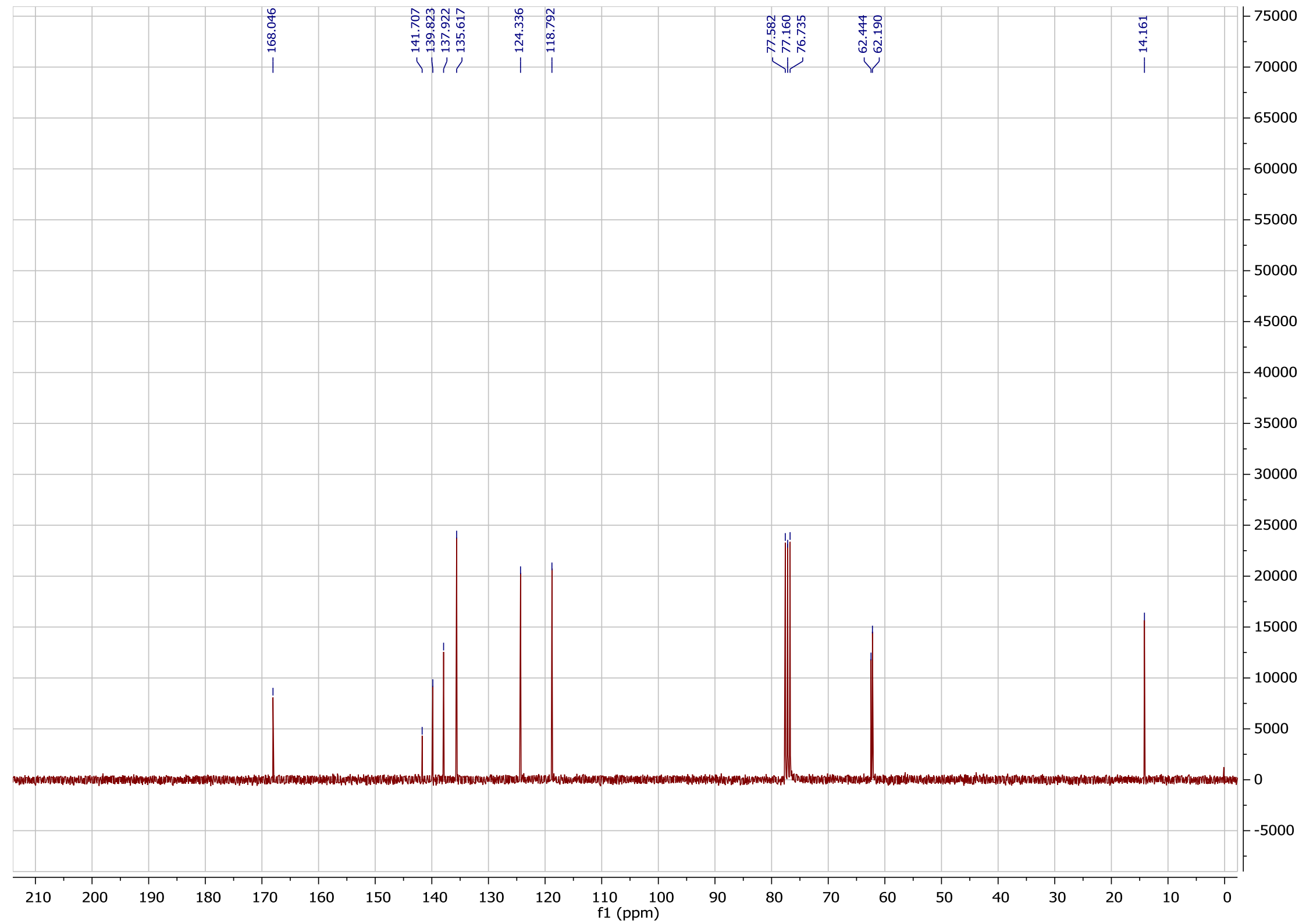


${ }^{1} \mathrm{H}$ NMR (300 MHz, $\left.\mathrm{CDCl}_{3}\right)$ : Compound 15

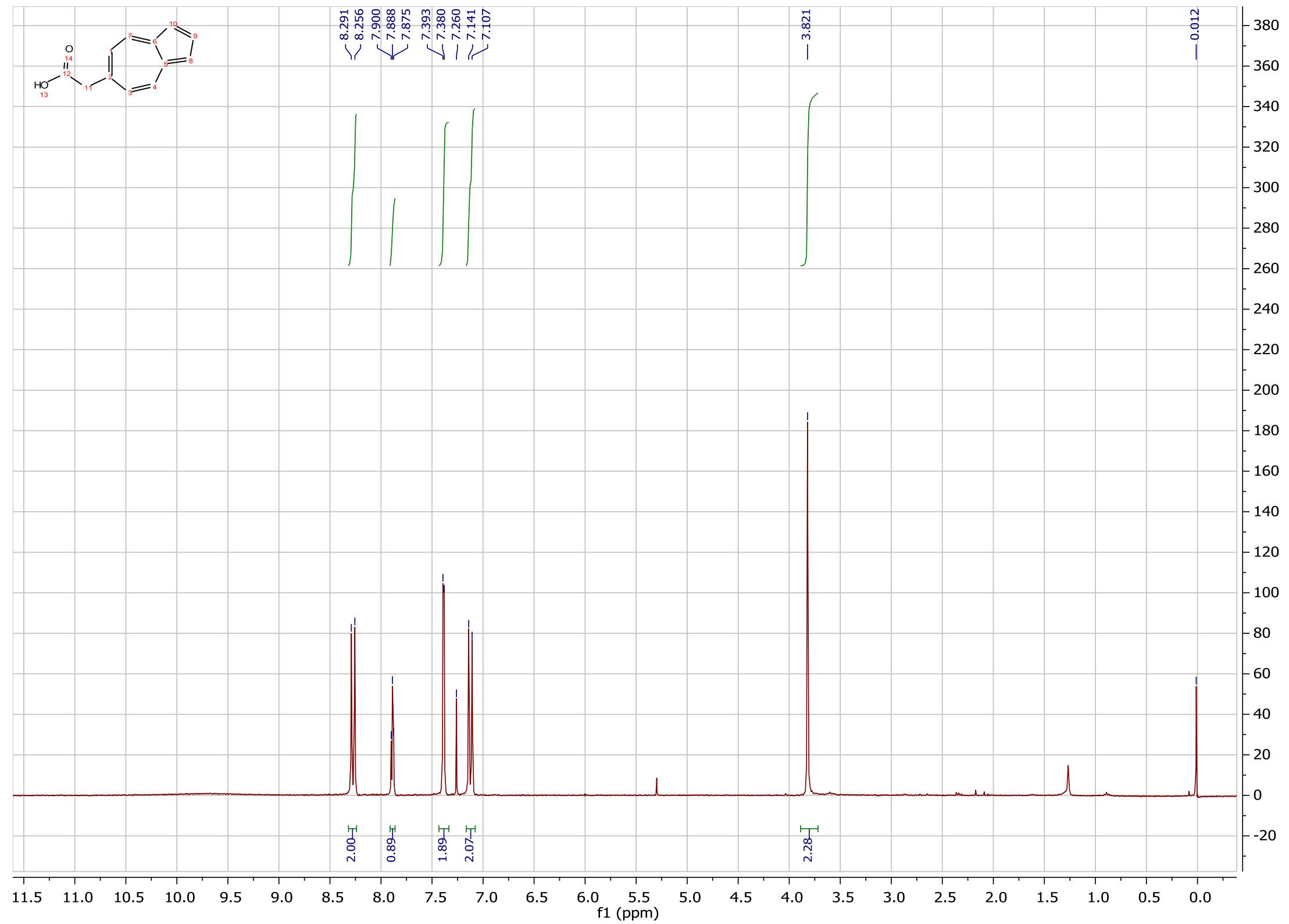


${ }^{13}$ C NMR (75 MHz, $\mathrm{CDCl}_{3}$ ): Compound 15
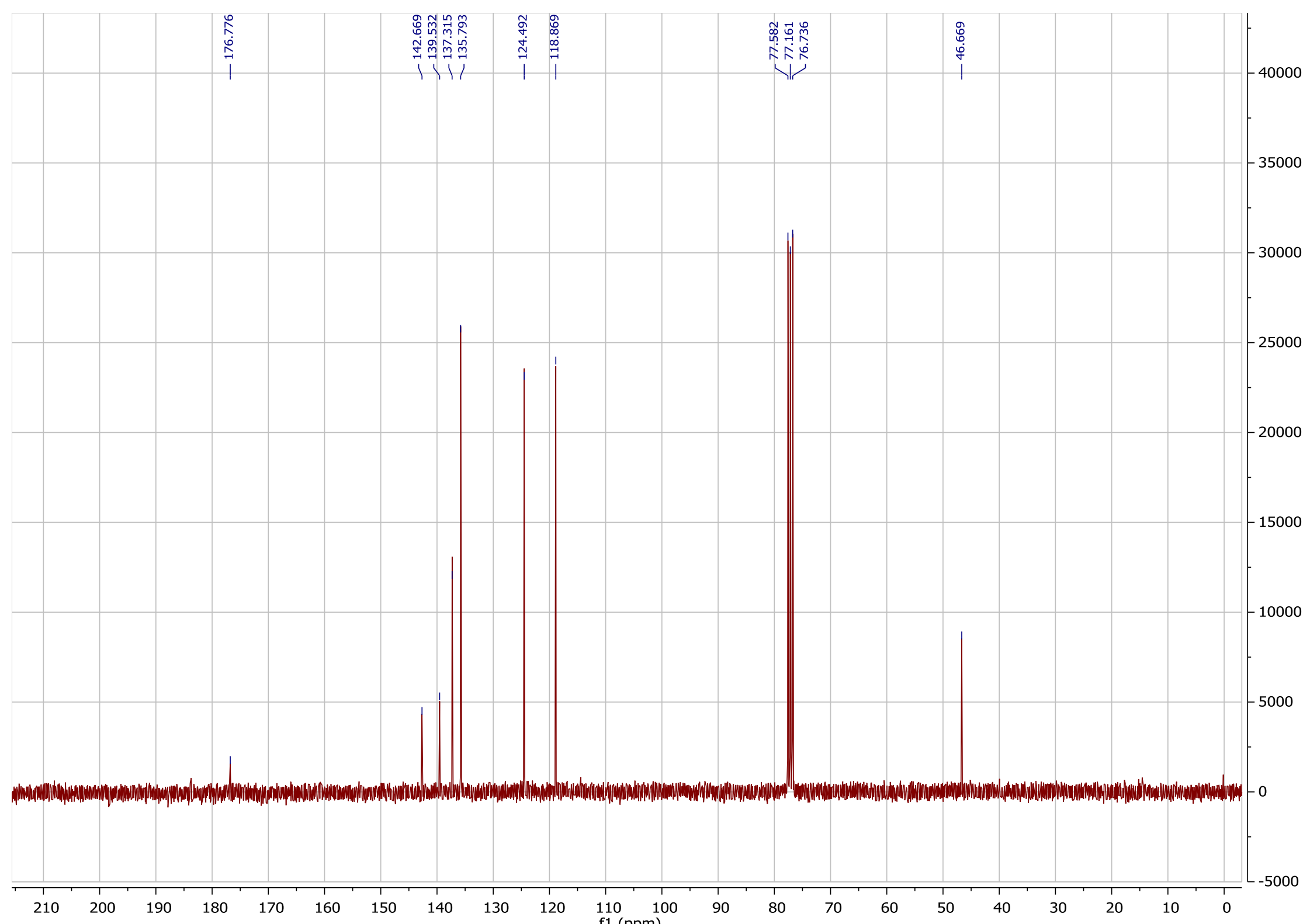
${ }^{1}$ H NMR (300 MHz, acetone- $d_{6}$ ): Compound 16

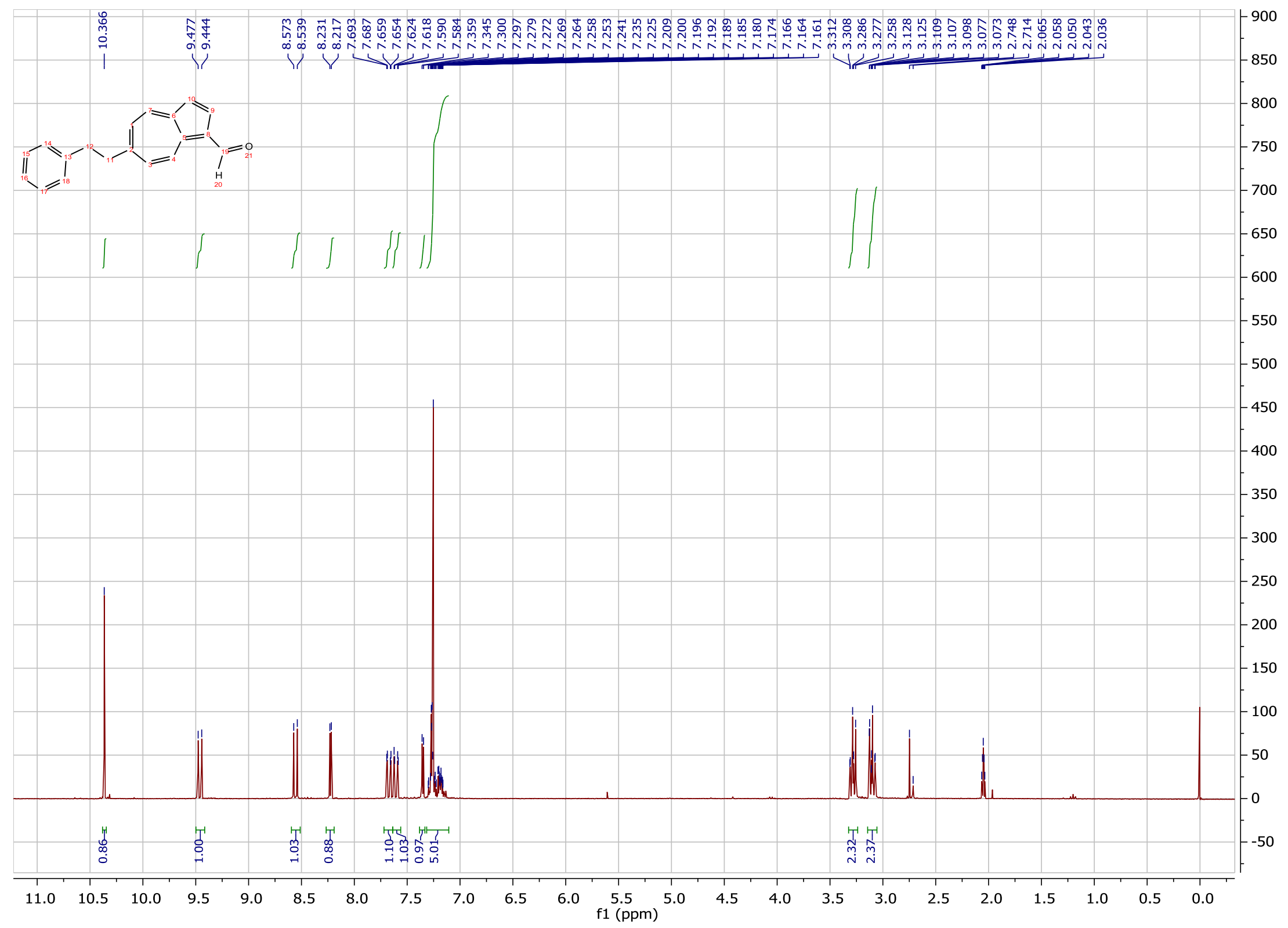


${ }^{13}$ C NMR (75 MHz, acetone- $\left.d_{6}\right)$ : Compound 16

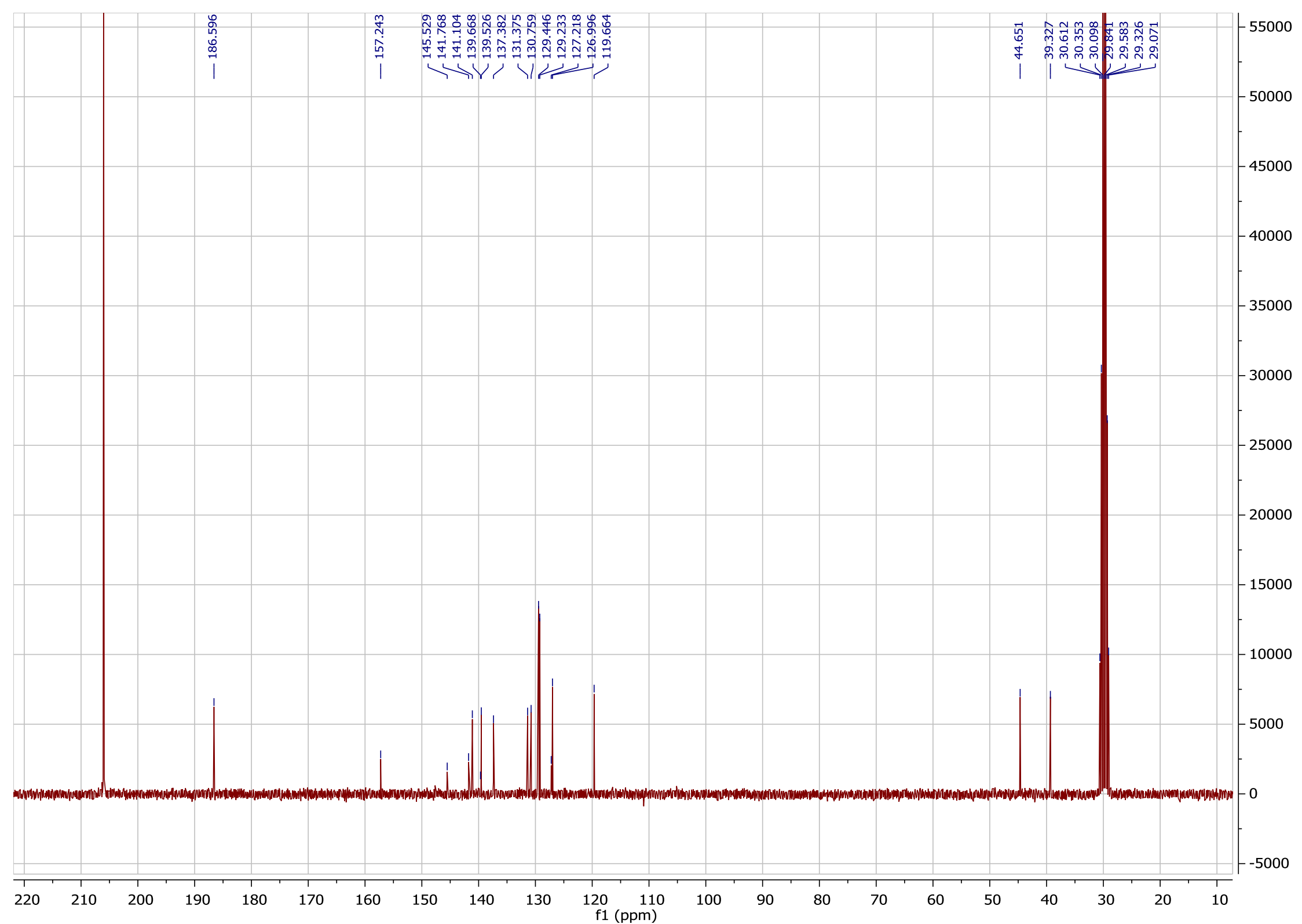


${ }^{1}$ H NMR (300 MHz, acetone- $d_{6}$ ): Compound 17

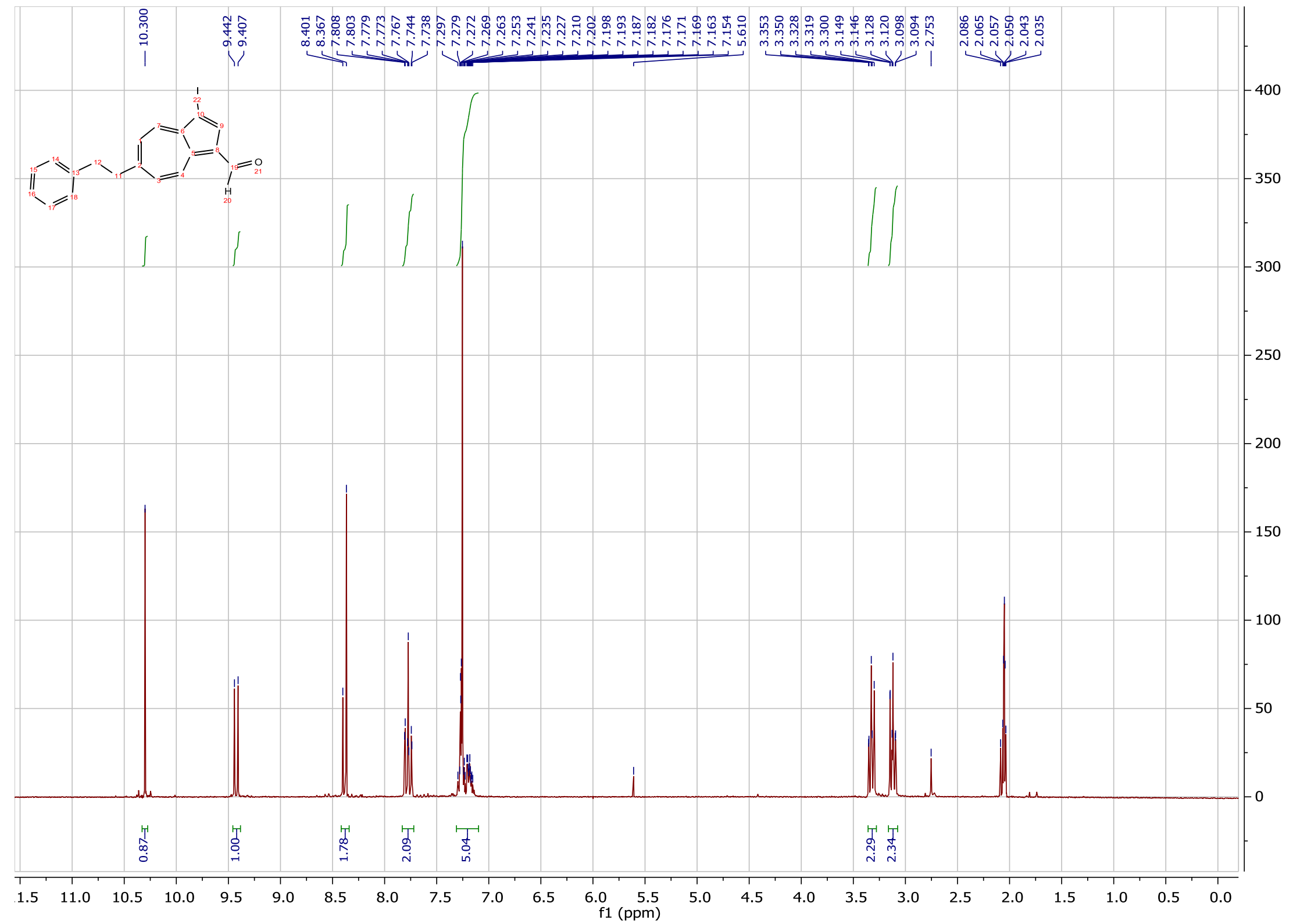


${ }^{13}$ C NMR (75 MHz, acetone- $\left.d_{6}\right)$ : Compound 17

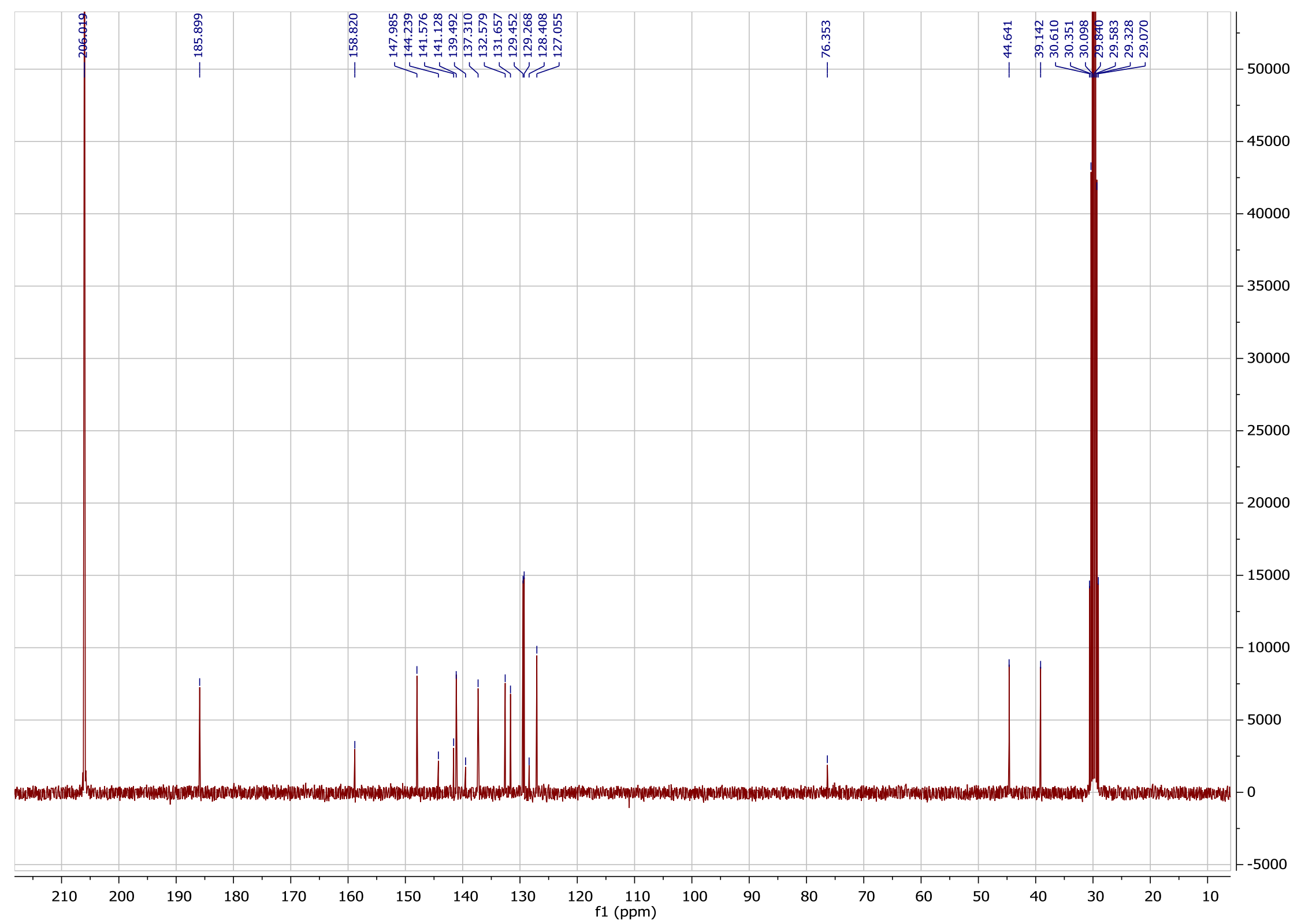


${ }^{1}$ H NMR (300 MHz, acetone- $\left.d_{6}\right)$ : Compound 18

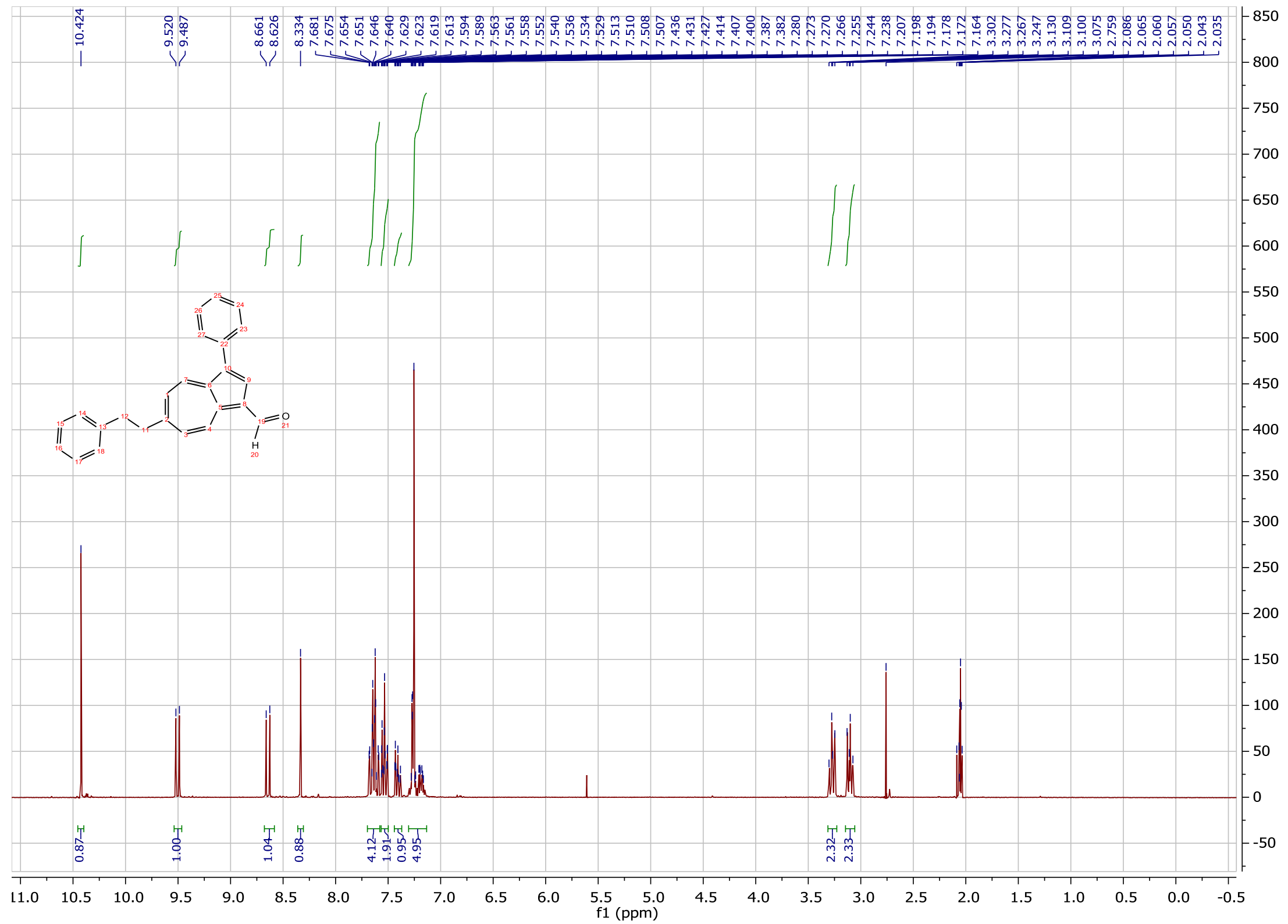


${ }^{13}$ C NMR (75 MHz, acetone- $\left.d_{6}\right)$ : Compound 18

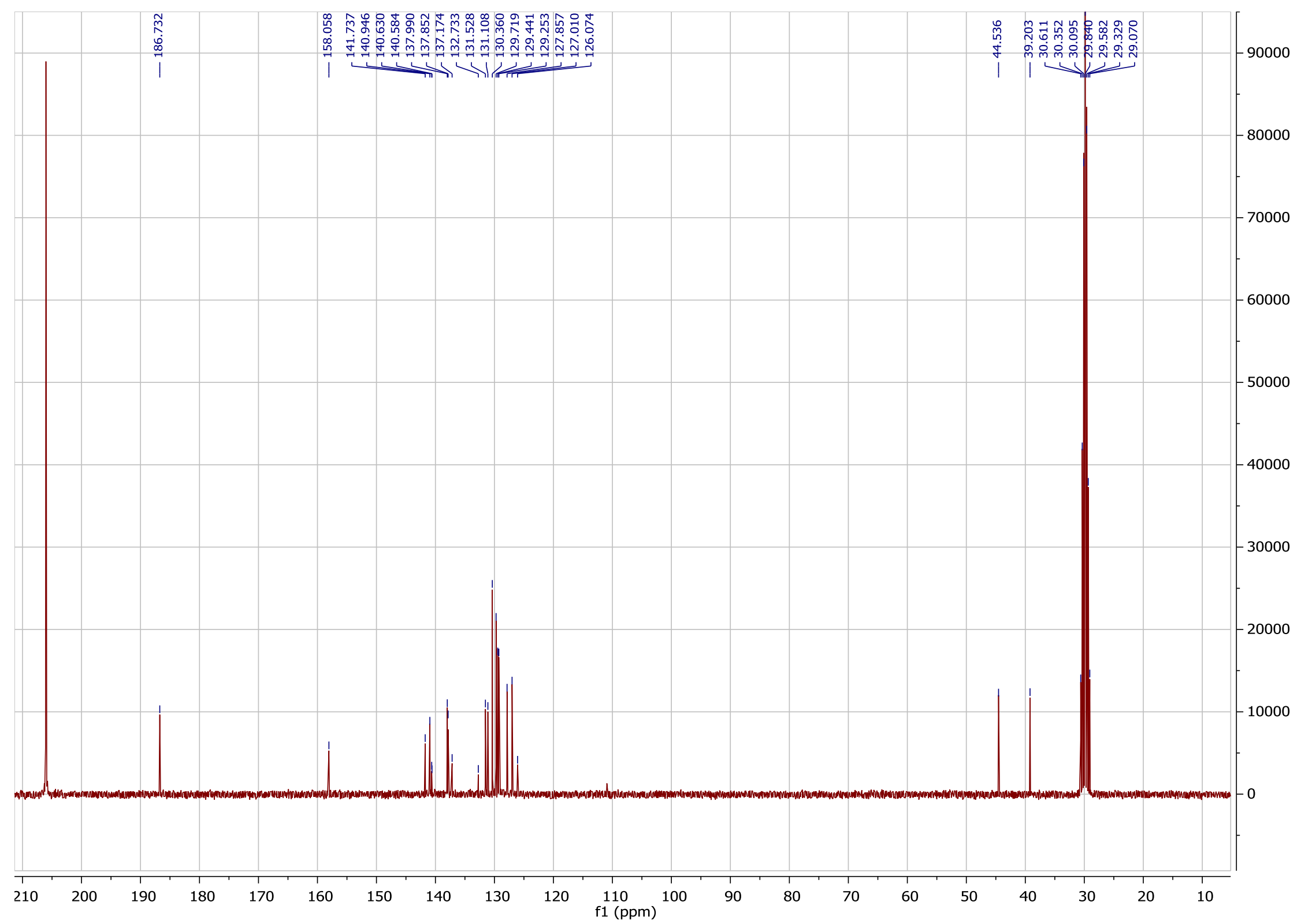


${ }^{1}$ H NMR (300 MHz, acetone- $d_{6}$ ): Compound 19

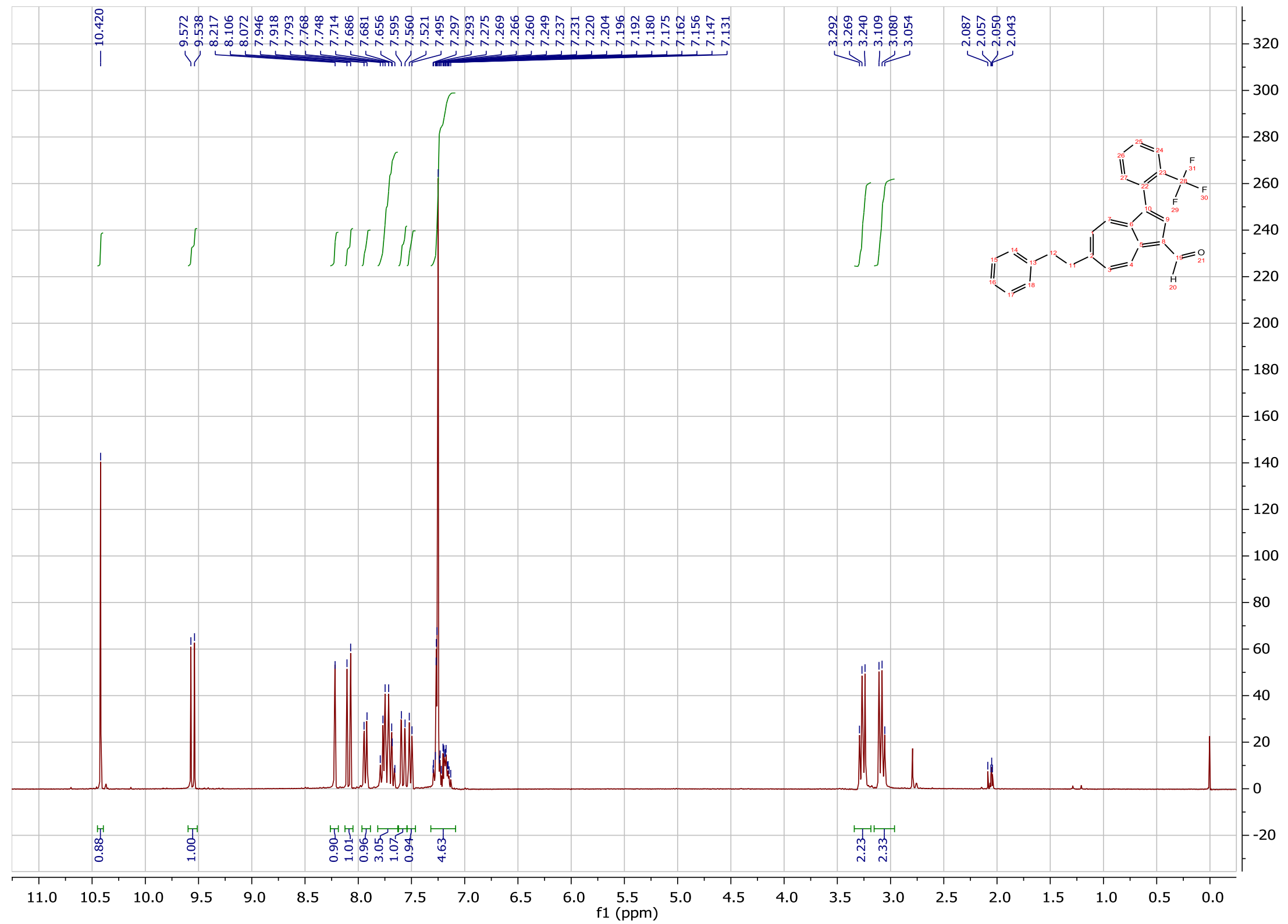


${ }^{13}$ C NMR (75 MHz, acetone- $\left.d_{6}\right)$ : Compound 19

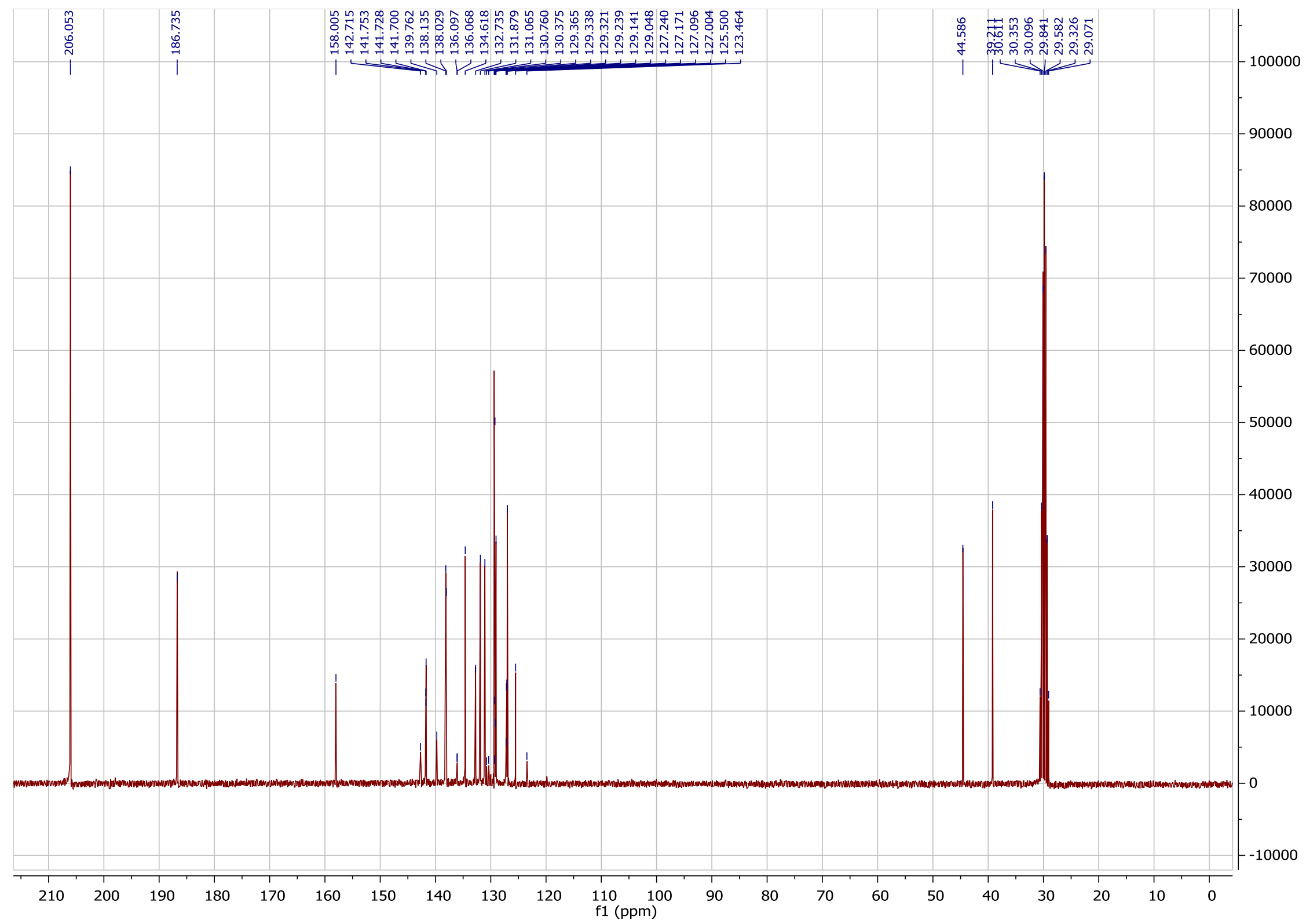


${ }^{1}$ H NMR (300 MHz, acetone- $d_{6}$ ): Compound 20

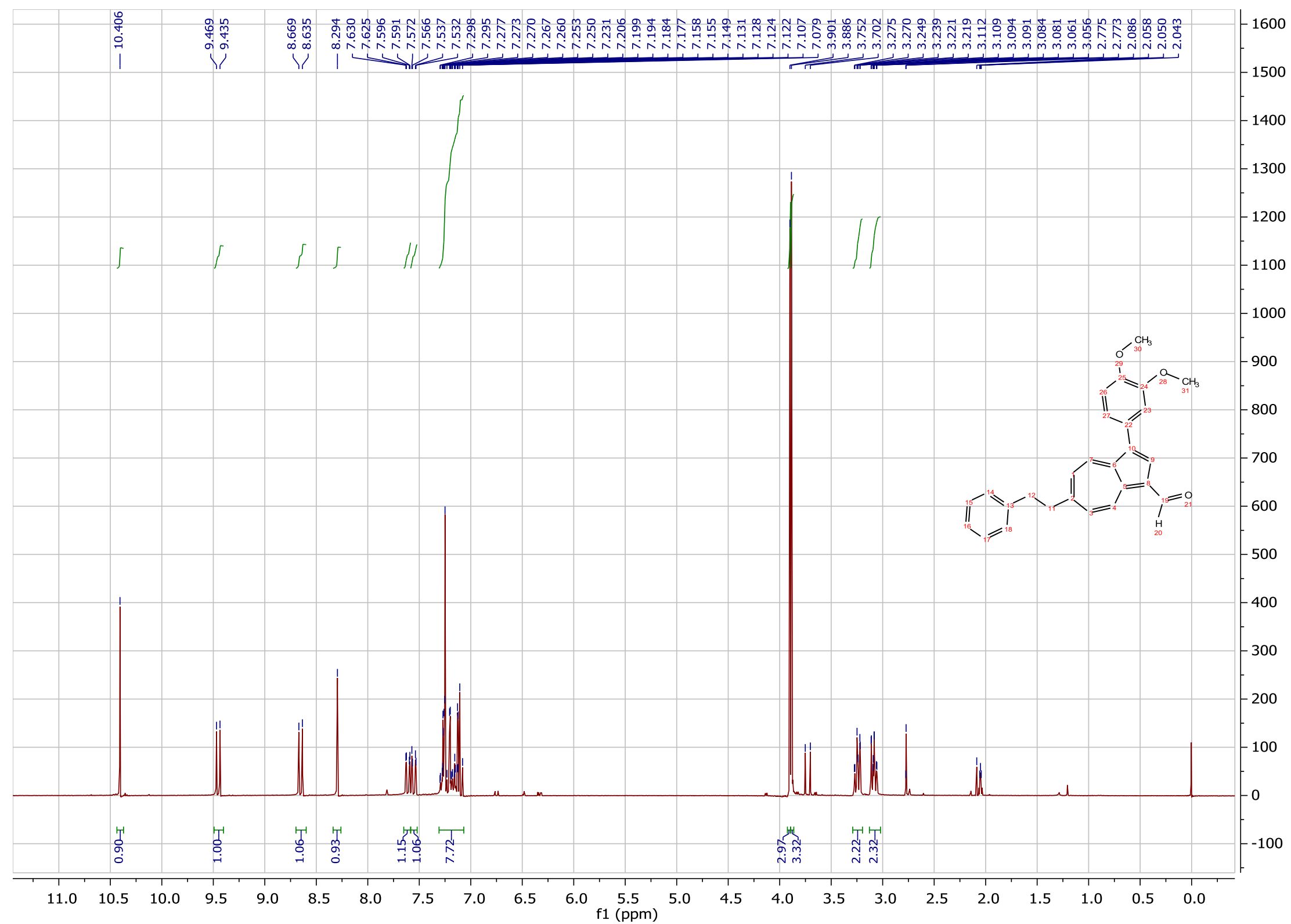


${ }^{13}$ C NMR (75 MHz, acetone- $\left.d_{6}\right)$ : Compound 20

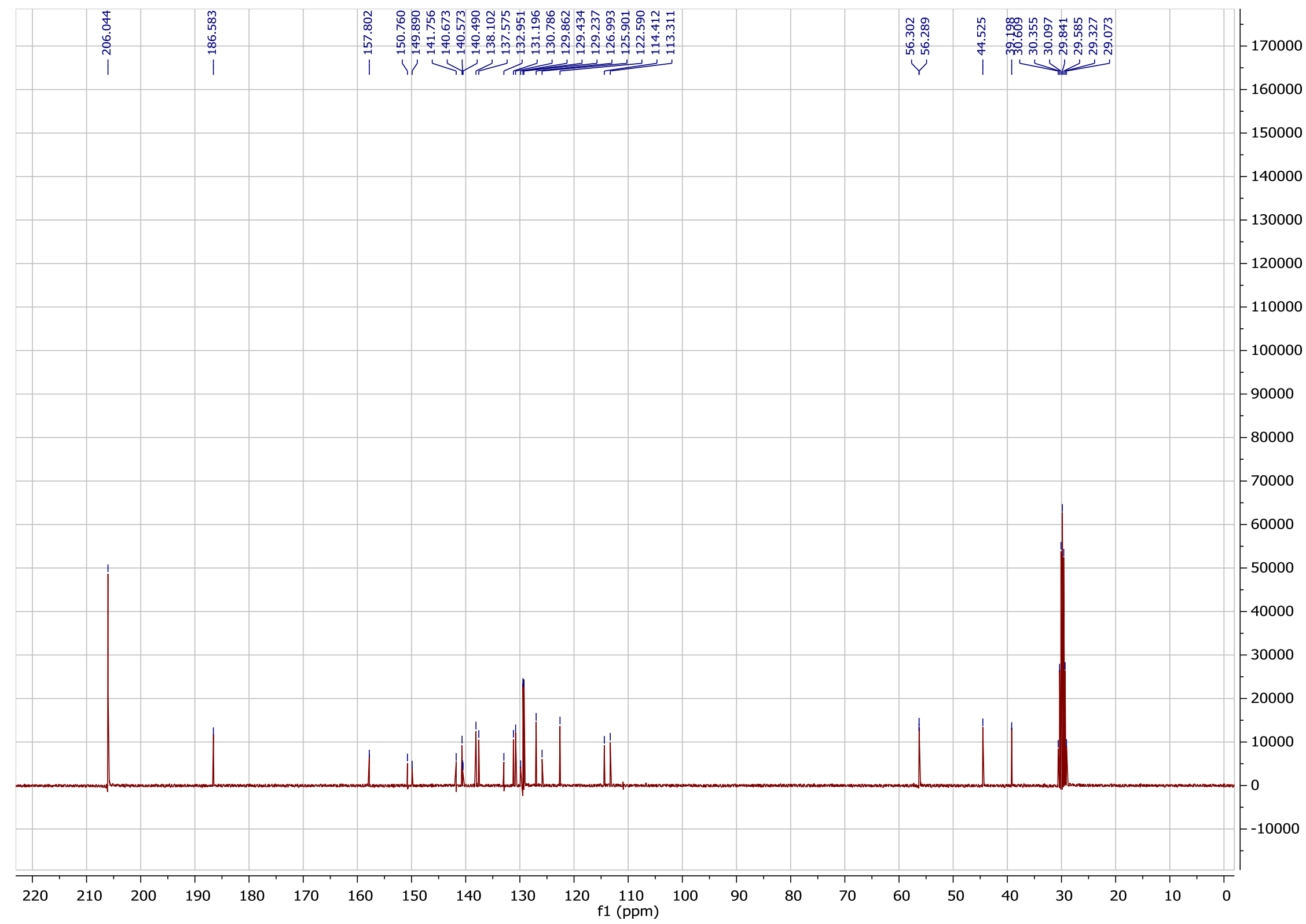


${ }^{1}$ H NMR (300 MHz, acetone- $\left.d_{6}\right)$ : Compound 21

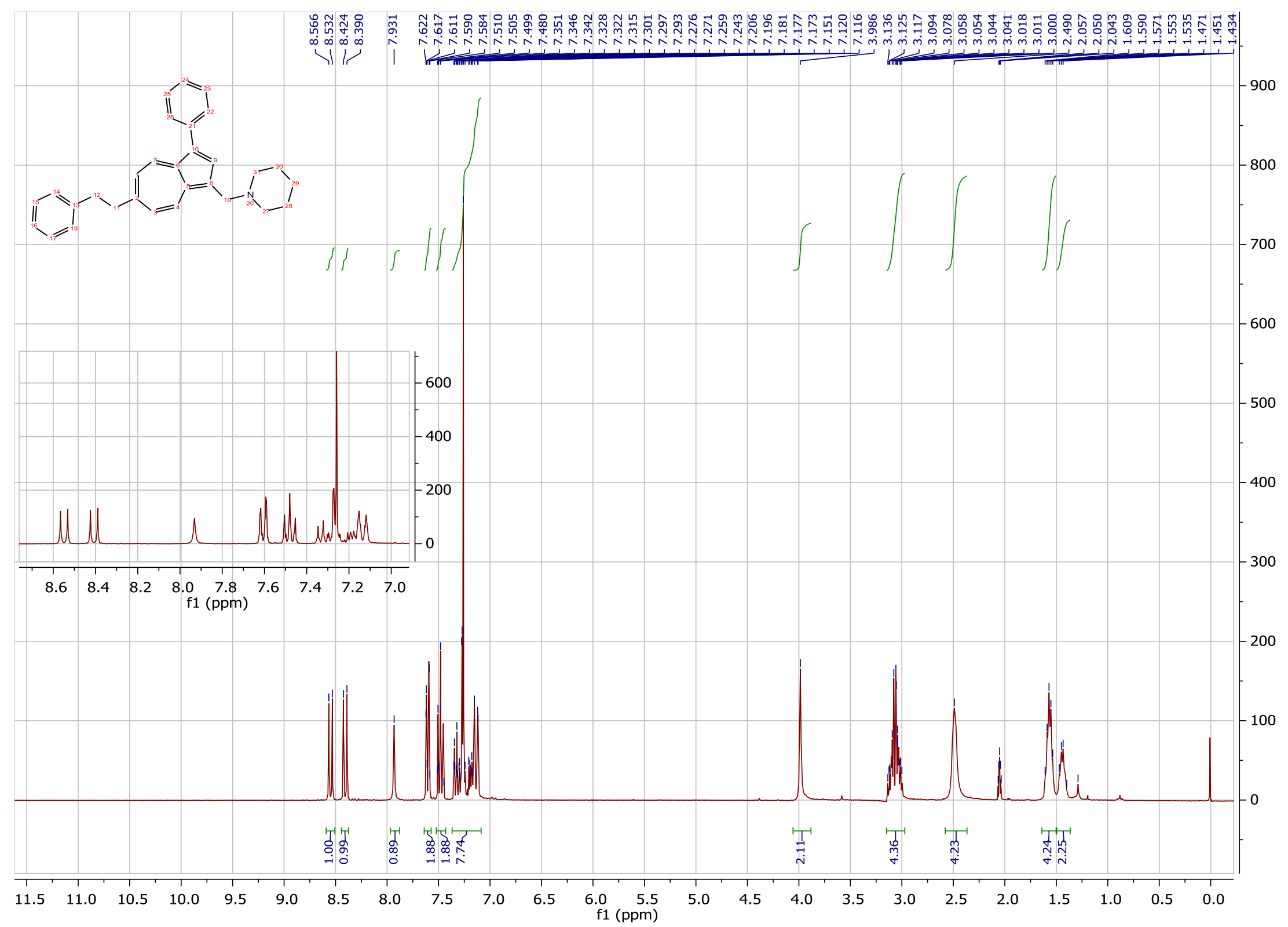


${ }^{13} \mathrm{C}$ NMR (75 MHz, acetone- $d_{6}$ ): Compound 21

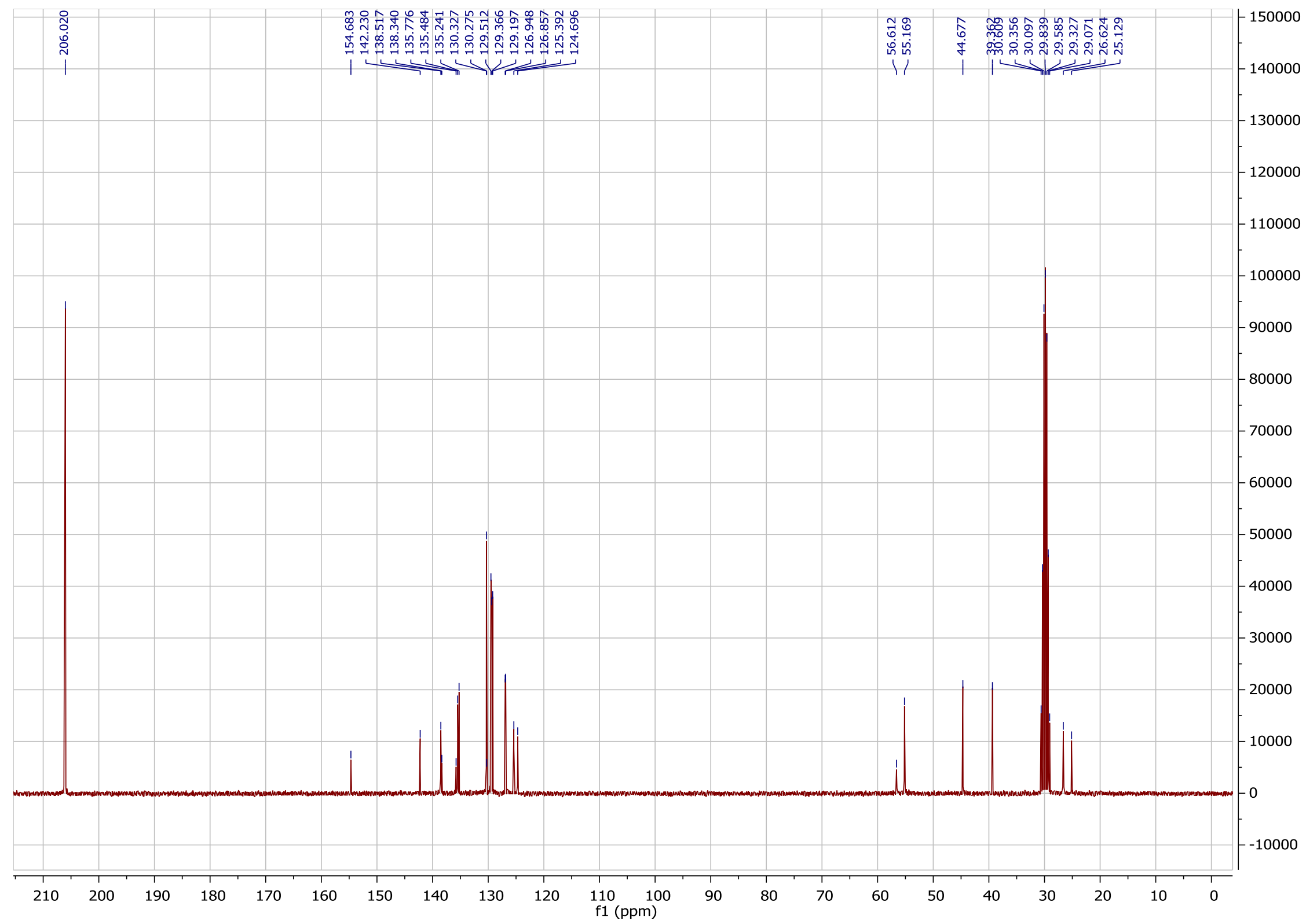


${ }^{1}$ H NMR (300 MHz, acetone- $d_{6}$ ): Compound 22

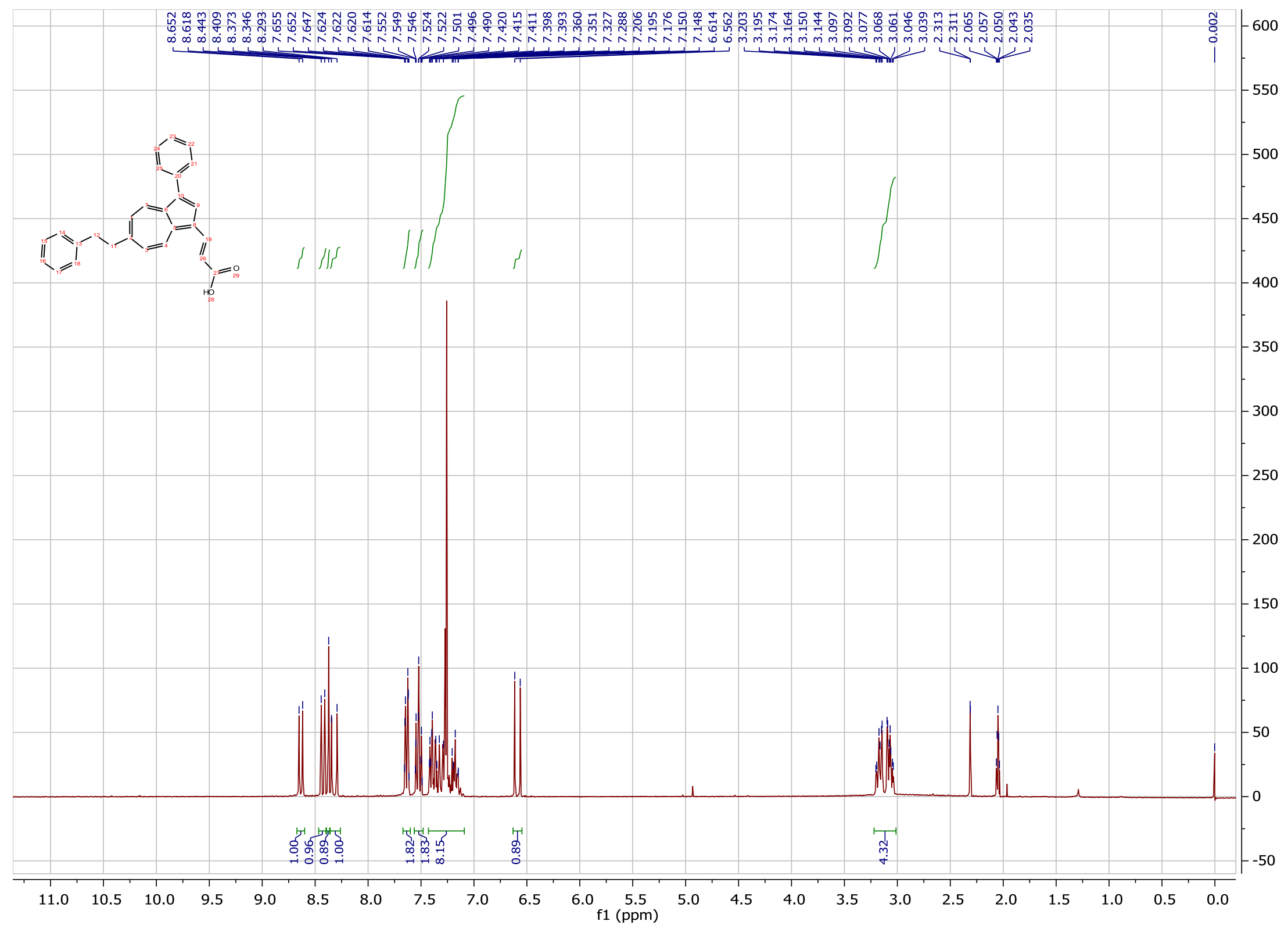


${ }^{13}$ C NMR (75 MHz, acetone- $\left.d_{6}\right)$ : Compound 22

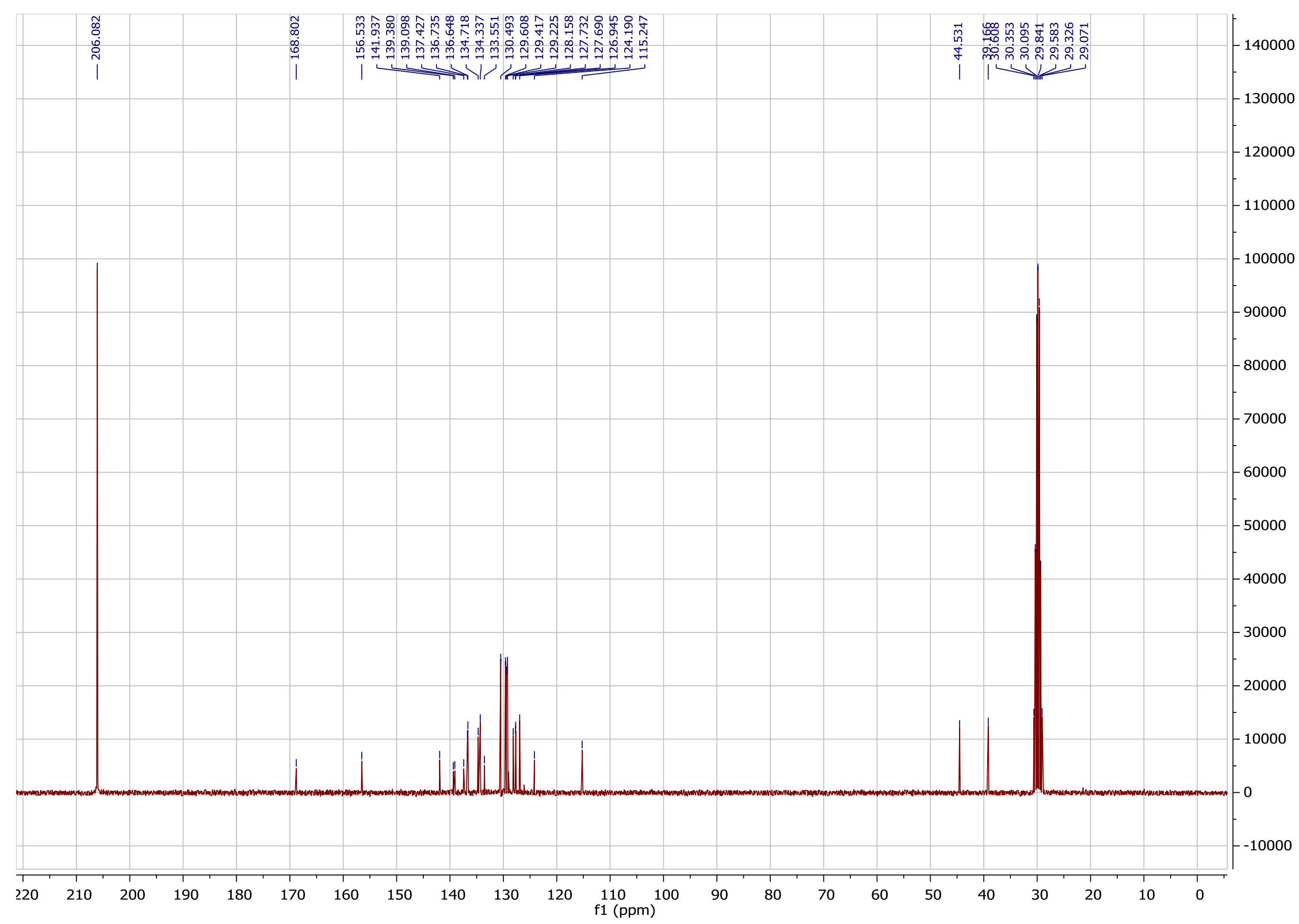


${ }^{1}$ H NMR (300 MHz, acetone- $d_{6}$ ): Compound 23

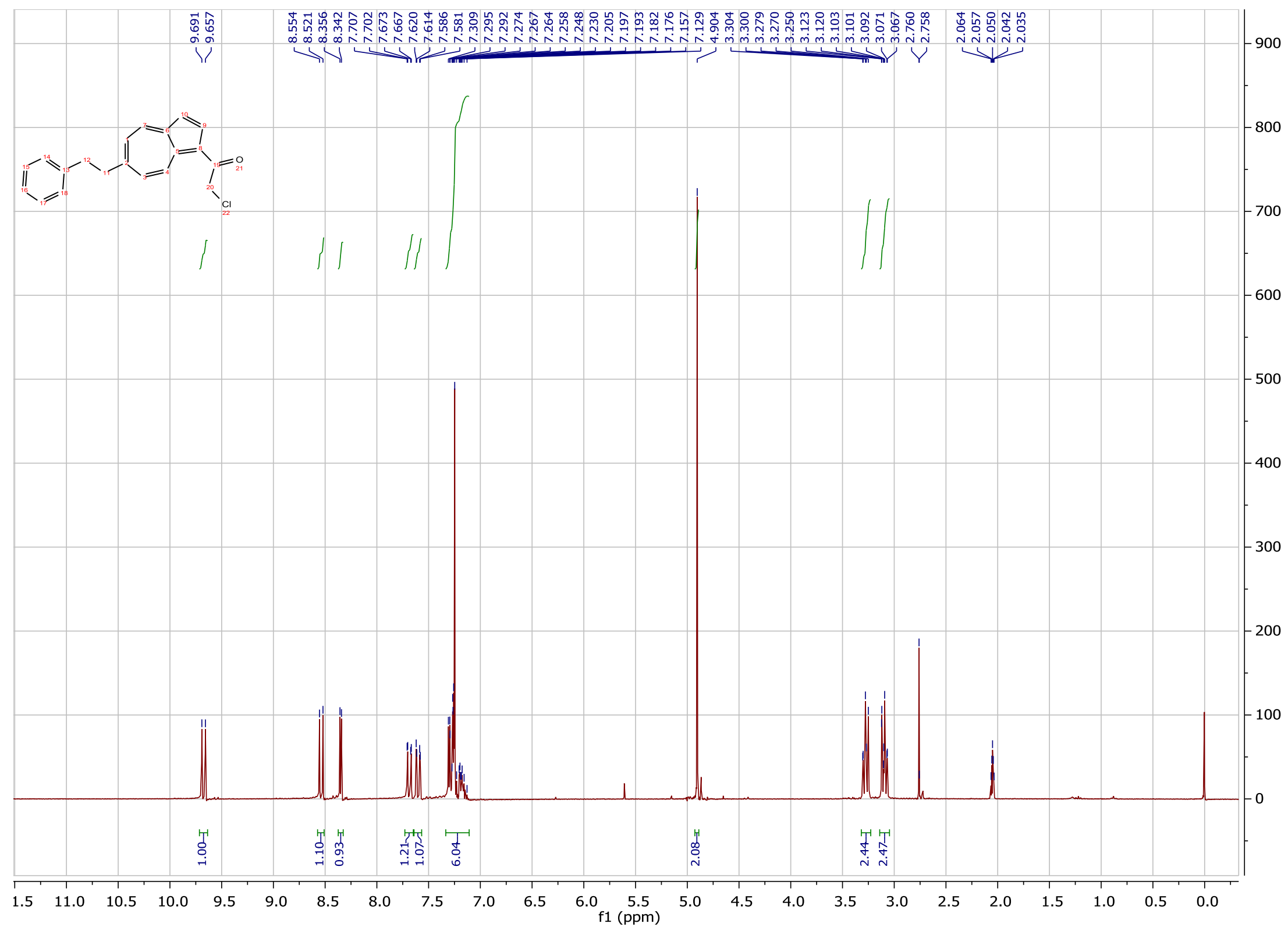


${ }^{13}$ C NMR (75 MHz, acetone- $\left.d_{6}\right)$ : Compound 23

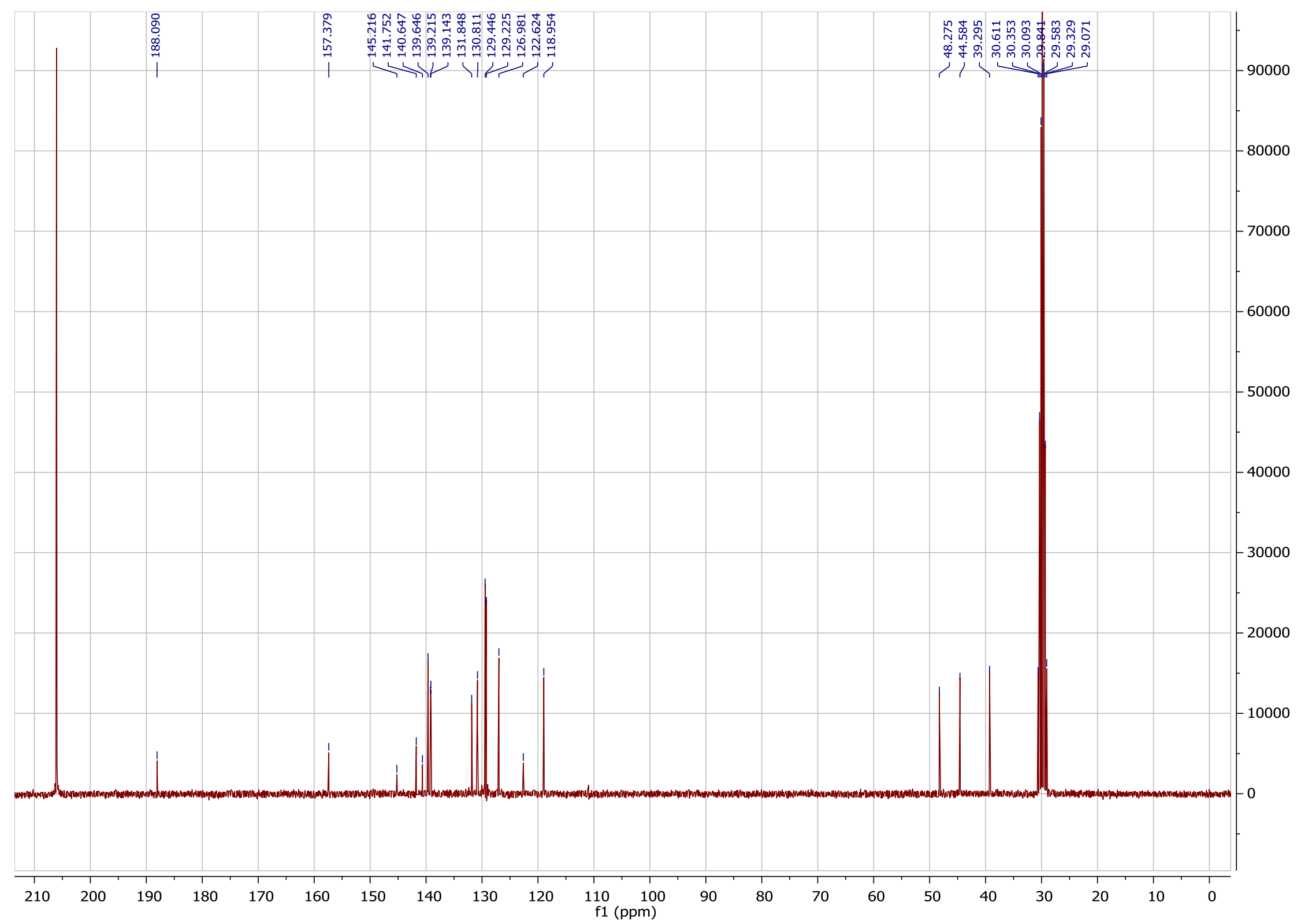


${ }^{1}$ H NMR (300 MHz, acetone- $d_{6}$ ): Compound 24

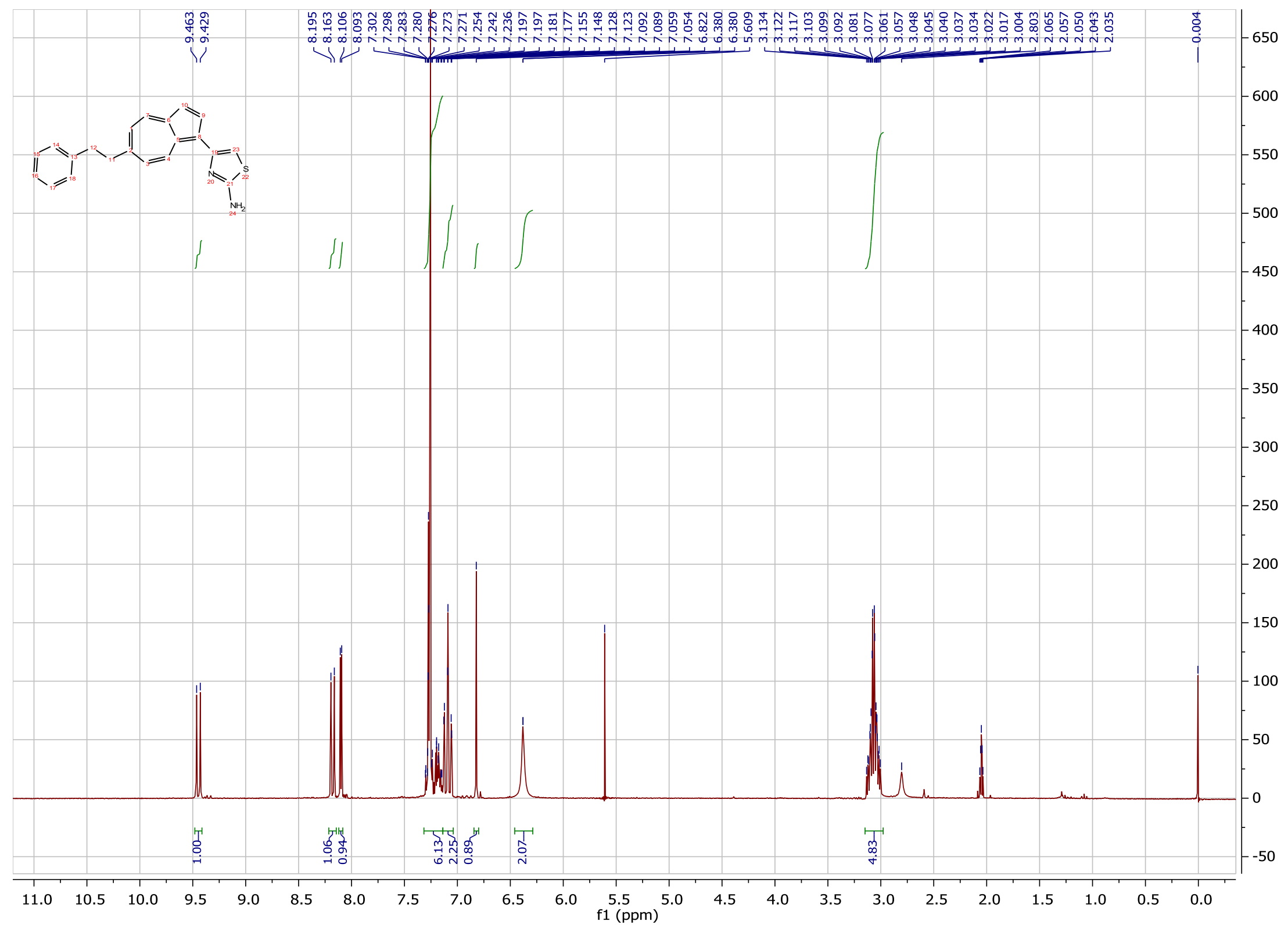


${ }^{13}$ C NMR (75 MHz, acetone- $\left.d_{6}\right)$ : Compound 24

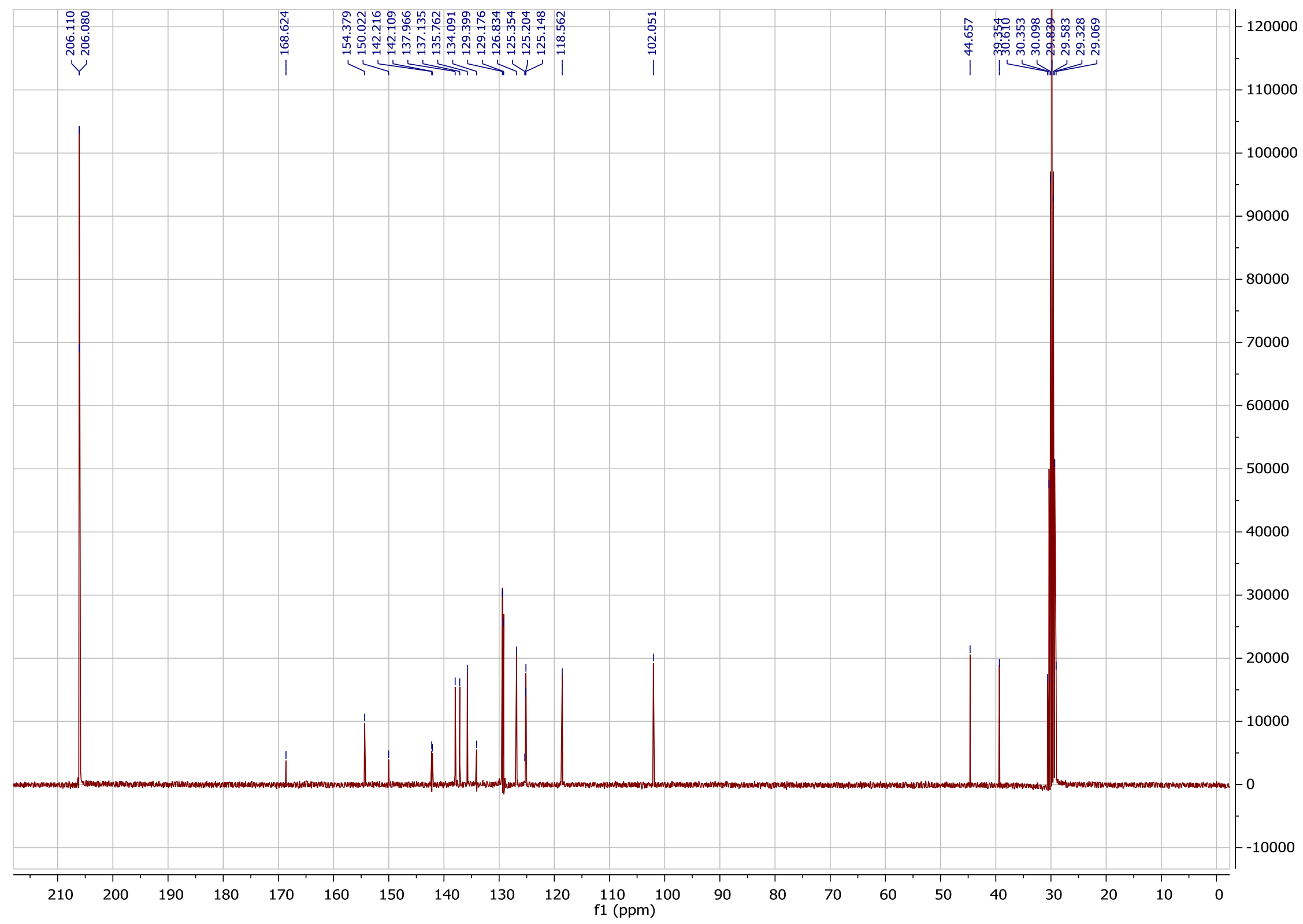


${ }^{1}$ H NMR (300 MHz, acetone- $d_{6}$ ): Compound 26

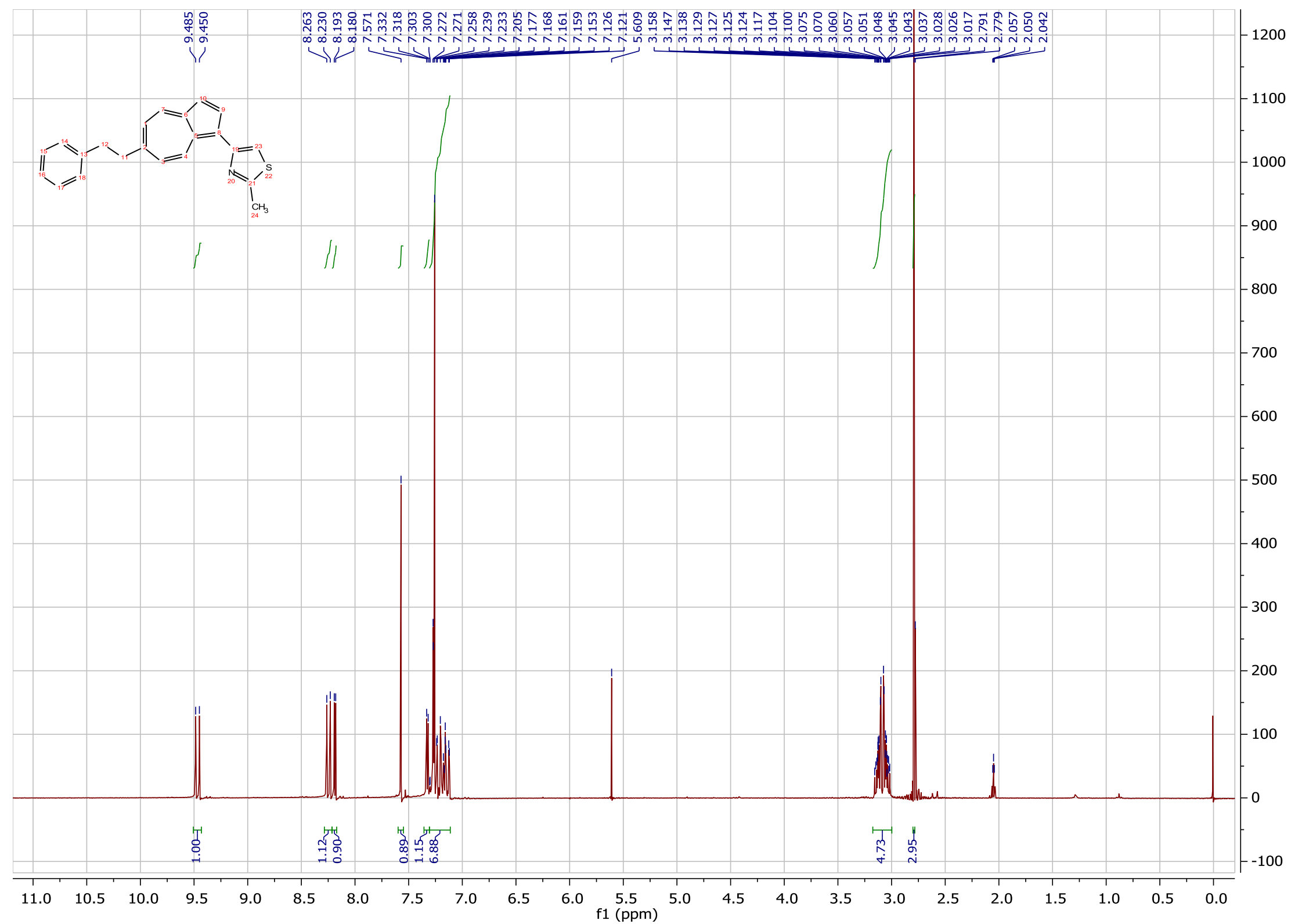


${ }^{13}$ C NMR (75 MHz, acetone- $\left.d_{6}\right)$ : Compound 26

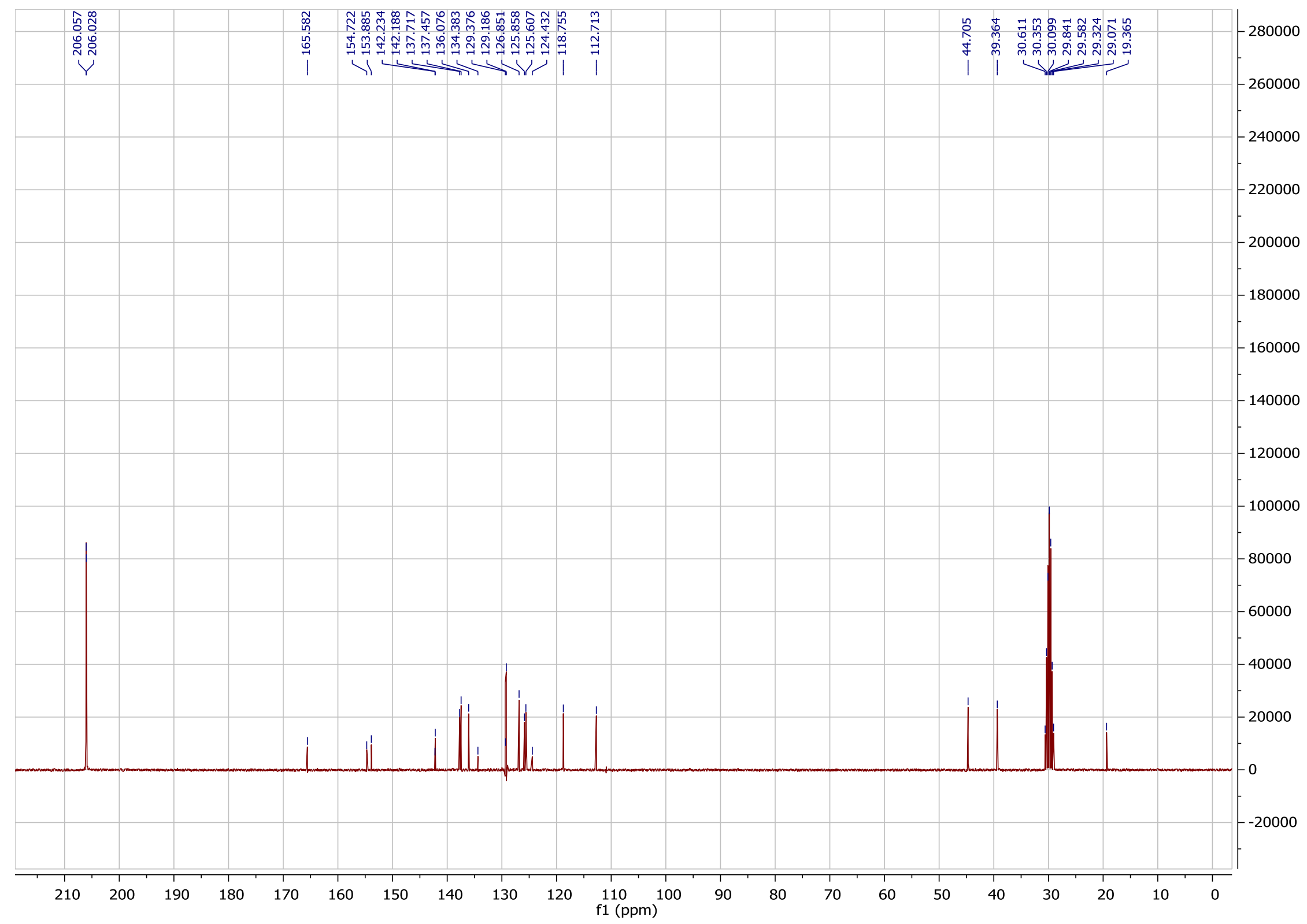


${ }^{1}$ H NMR (300 MHz, acetone- $d_{6}$ ): Compound 27

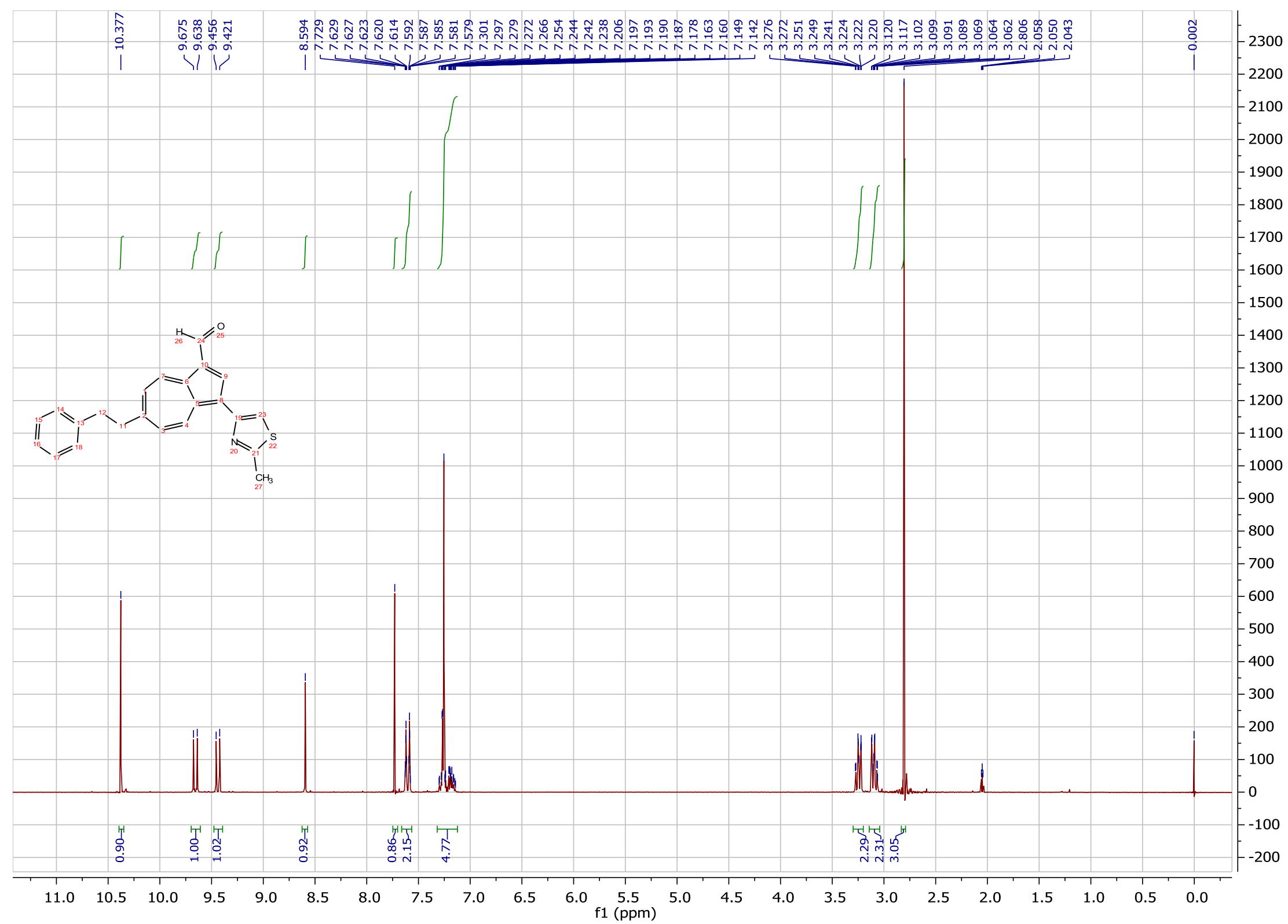


${ }^{13}$ C NMR (75 MHz, acetone- $\left.d_{6}\right)$ : Compound 27

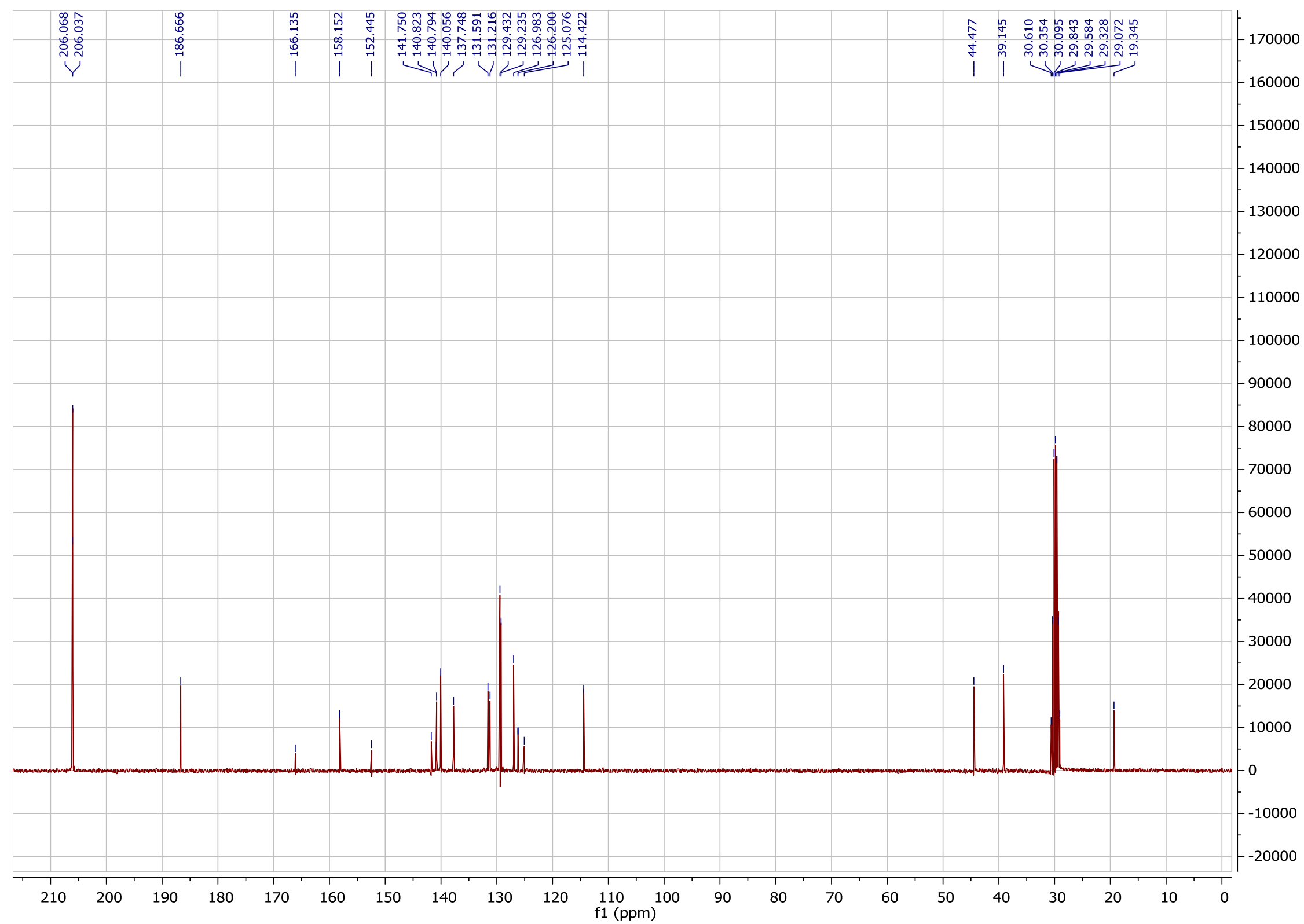


${ }^{1}$ H NMR (300 MHz, acetone- $d_{6}$ ): Compound 28

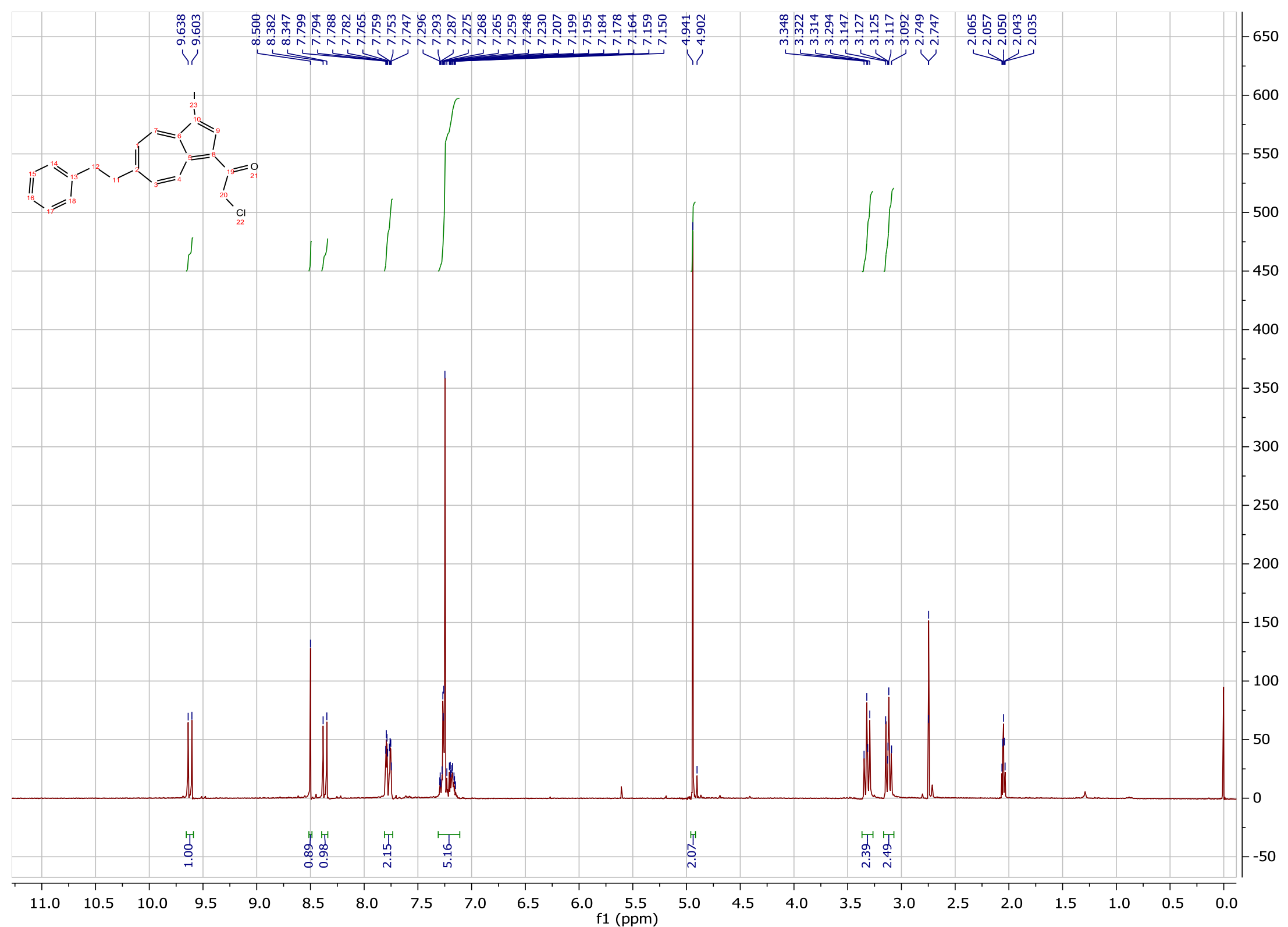




\section{${ }^{13} \mathrm{C}$ NMR (75 MHz, acetone- $\left.d_{6}\right)$ : Compound 28}

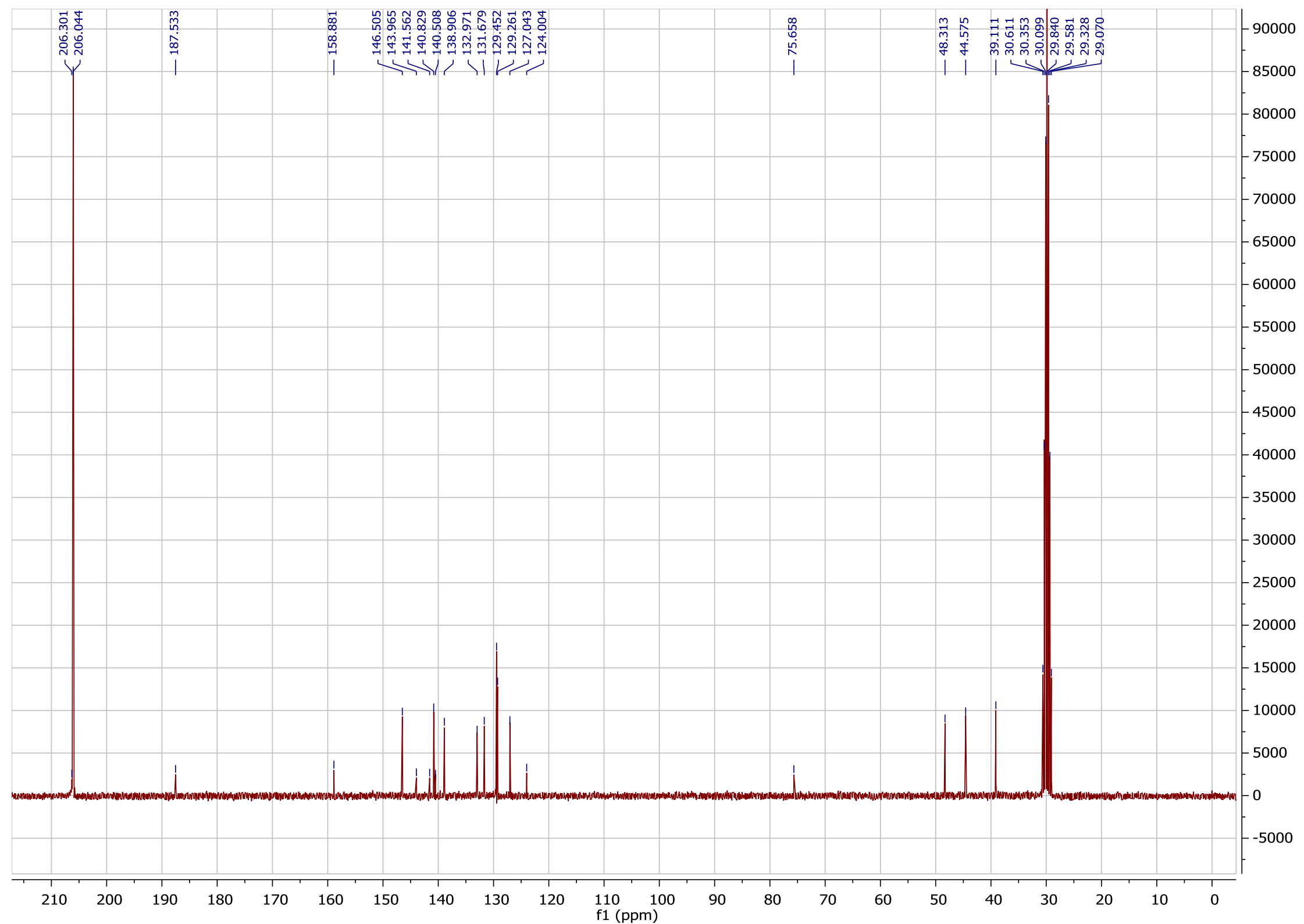


${ }^{1}$ H NMR (300 MHz, acetone- $\left.d_{6}\right)$ : Compound 31

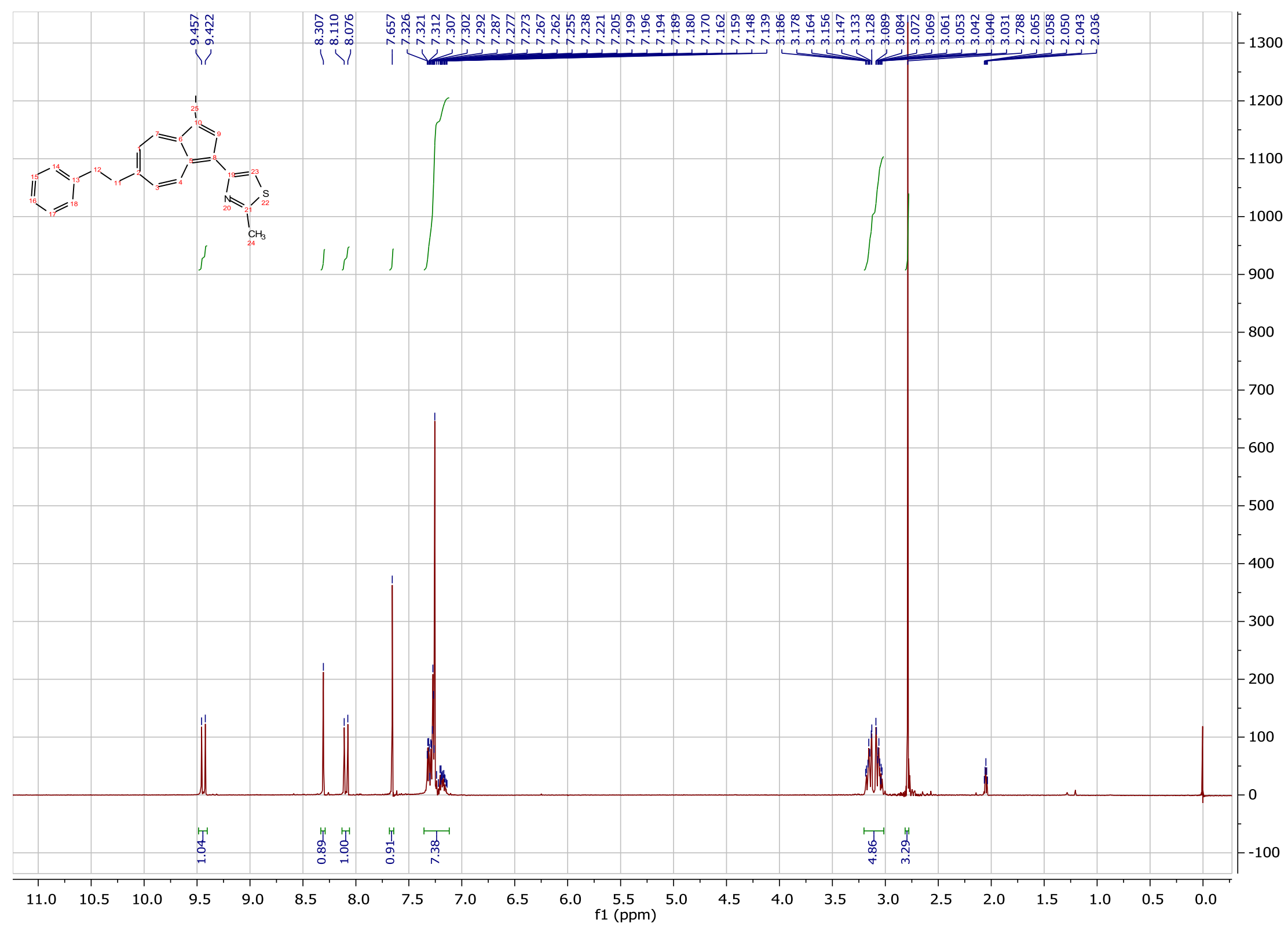


${ }^{13}$ C NMR (75 MHz, acetone- $\left.d_{6}\right)$ : Compound 31

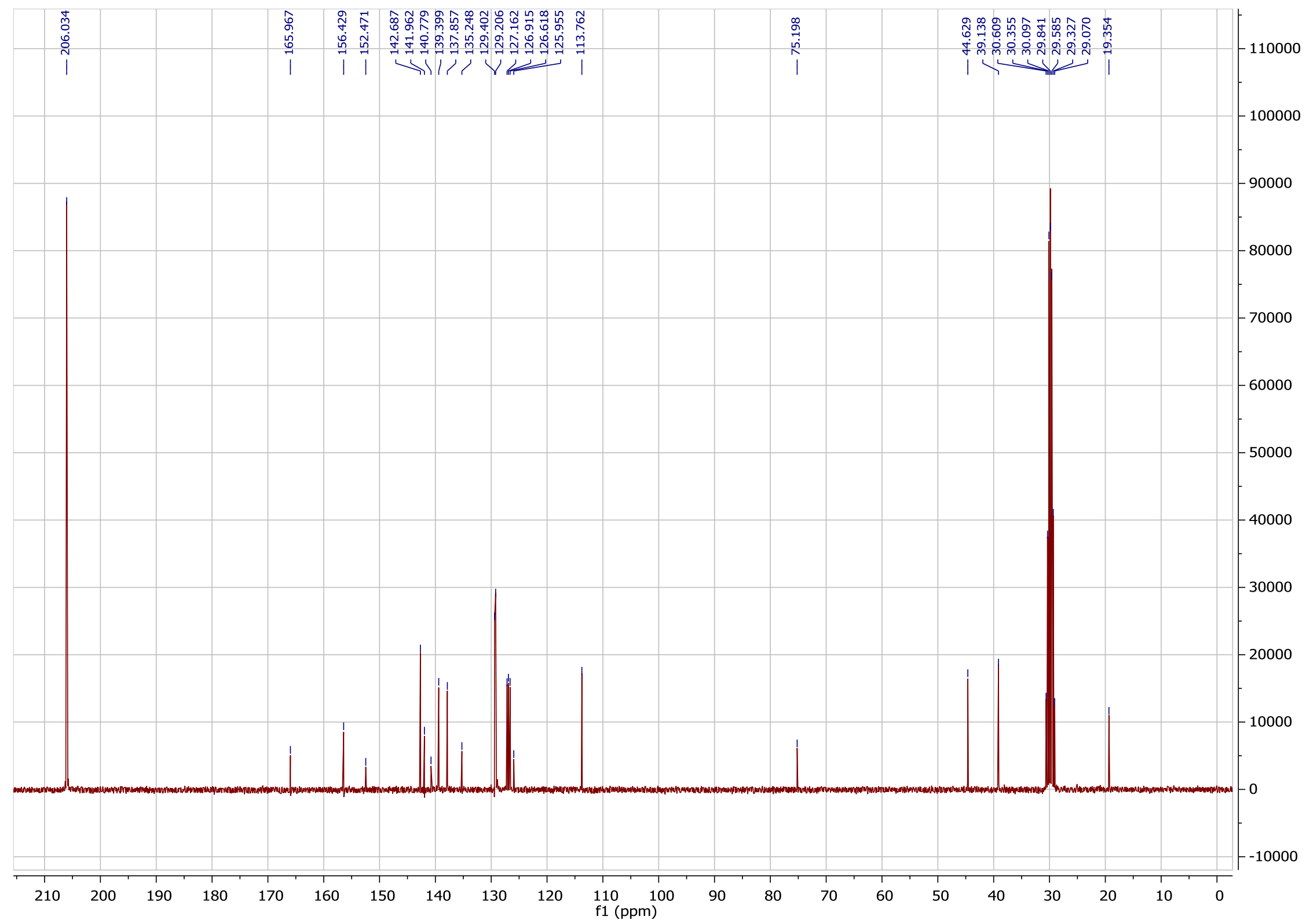


${ }^{1}$ H NMR (300 MHz, acetone- $d_{6}$ ): Compound 32

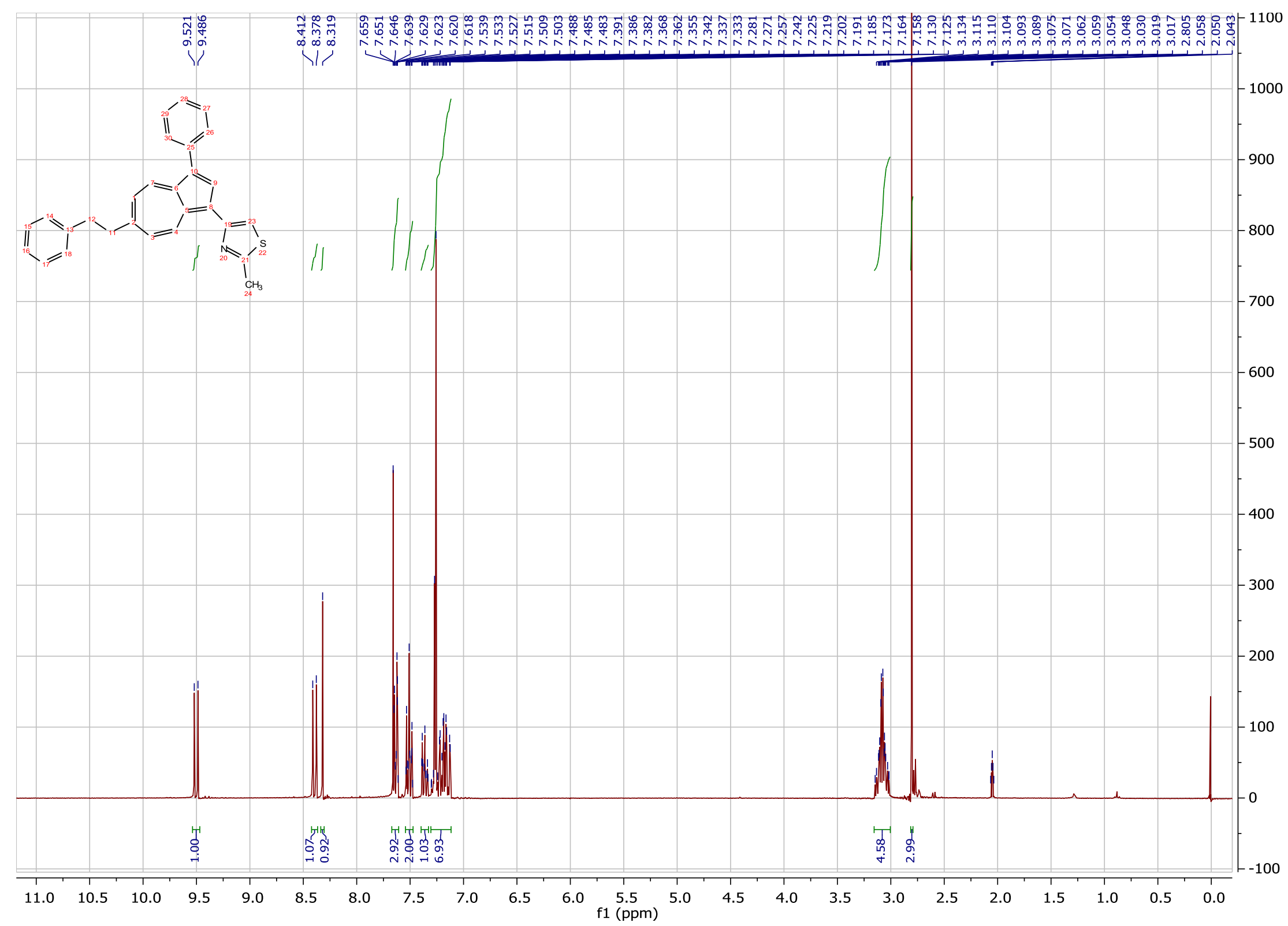




\section{${ }^{13} \mathrm{C}$ NMR (75 MHz, acetone- $\left.d_{6}\right)$ : Compound 32}

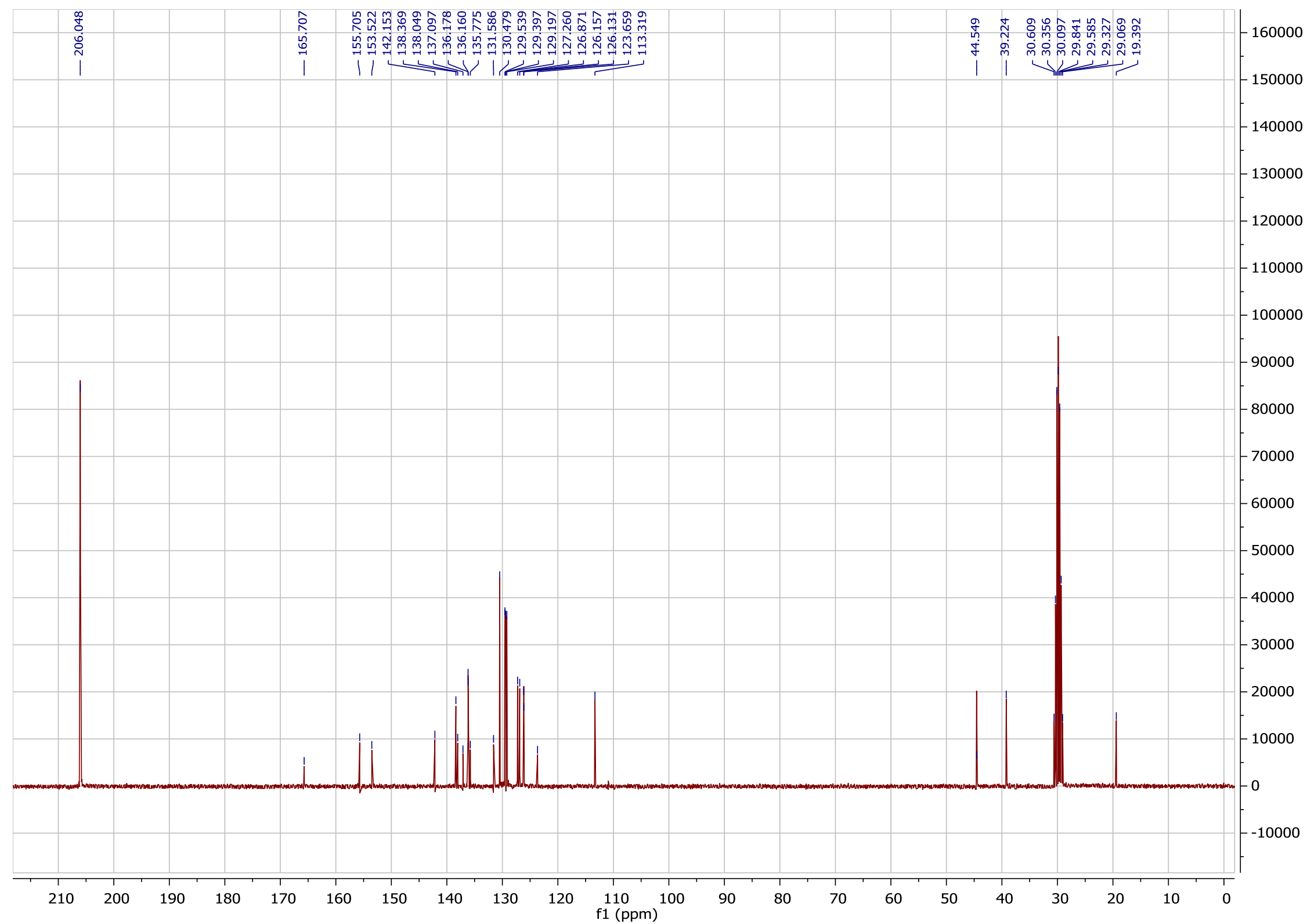

